Journal of Thermoplastic Composite Materials

2005; 18(5) : 417-443

http://dx.doi.org/10.1177/0892705705054397

(c) 2005 SAGE Publications
Archimer, archive institutionnelle de l'Ifremer http://www.ifremer.fr/docelec/

\title{
Thermoplastic Composite Cylinders for Underwater Applications
}

\author{
Peter Davies*, Luc Riou, Florence Mazeas, Philippe Warnier \\ Marine Technology Department, IFREMER Brest Centre, France \\ *: Corresponding author : peter.davies@ifremer.fr
}

\begin{abstract}
A study of thermoplastic matrix composites has been performed to investigate their use in underwater applications such as oceanography, submarine, and sub-sea offshore structures. This article first presents six candidate materials. Results from simple mechanical and seawater aging screening tests on flat specimens are then described. Glass/epoxy and carbon/epoxy composites are used as reference materials. Two materials emerged from this process, glass/PEI and carbon/PEEK. Cylinders of both were manufactured and subjected to hydrostatic pressure tests, and results are compared to those for glass/epoxy and carbon/epoxy cylinders of similar geometry. The carbon/PEEK material appeared most promising. It resisted pressures in excess of $90 \mathrm{MPa}$ and was retained for damage tolerance assessment studies. Drop weight impact damage zones were smaller in carbon/PEEK than carbon/epoxy for the same impact energies but the loss in residual collapse strength was more rapid in the thermoplastic composite. This was attributed to a change in failure mode, impact damage initiated a local buckling failure.
\end{abstract}

Keywords: cylinder $\bullet$ hydrostatic pressure $\bullet$ aging $\bullet$ carbon/PEEK $\bullet$ glass/PEl $\bullet$ damage tolerance 


\section{INTRODUCTION}

Thermoplastic composites have been available for many years. Several textbooks describe the development of these materials, which may offer significant advantages over traditional thermoset matrix composites [1-3]. These include superior toughness, repairability and the potential to produce very large structures without the out-time and curing problems associated with epoxy resins. After many years of evaluation these materials are now finding their first applications in civil aircraft. Some developments have also been reported for underwater applications. These have generally been for military applications, so few published details are available, but a special issue of this journal presented results from a US Navy study financed by what was then DARPA (Defense Advanced Research Projects Agency). That study concentrated on tape placement and several carbon reinforced thermoplastics were examined including PPS, PEI, PEEK and PEKK, and a number of cylinders were tested [4-6]. Further details of the thermoplastic composite tape placement technique were presented recently [7]. Most previous work has focussed on carbon fibre reinforced thermoplastics but for many less weight critical underwater applications glass reinforced composites are also attractive.

The use of composites at sea requires a thorough understanding of seawater aging mechanisms. Many studies have focussed on this aspect and several thermoplastic composites have been evaluated e.g. [8-11]. Thermoplastic composites can offer excellent long term durability but this is not necessarily the case and cannot be predicted theoretically, so tests are essential. An important additional requirement for deep sea applications, where high hydrostatic pressures are present, is the ability to resist biaxial compression. The pressure which acts on an immersed structure depends on the depth according to the expression [12]:

$$
\mathrm{P}=\mathrm{C}_{1} * \mathrm{H}+\mathrm{C}_{2} * \mathrm{H}^{2}
$$

$\mathrm{P}=$ pressure $(\mathrm{MPa})$

$\mathrm{H}=$ immersion depth $(\mathrm{m})$

Where $\mathrm{C}_{1}$ is equal to $0.01 \mathrm{MPa} / \mathrm{m}$ and $\mathrm{C}_{2}$ equal to $0.05 \times 10^{-6} \mathrm{MPa} / \mathrm{m}^{2}$.

Two failure modes can operate; for thin wall structures buckling may be critical, whereas for thicker wall dimensions a material compression failure may intervene. The transition between 
these two modes can be estimated theoretically using buckling analysis and thick laminate analysis with an appropriate material failure criterion. Gruber et al. [6] have performed such analyses and suggest that buckling failure will occur for a thickness to radius ratio below 0.095 for S2 glass/PEKK and below 0.1 for carbon/PEKK. The uncertainty in many of the input data for such calculations results in difficulty in defining this transition geometry exactly and there is also considerable controversy surrounding the appropriate criterion to use in the compression-compression sector of the axial stress / hoop stress failure envelope. Soden et al presented experimental data for glass/epoxy cylinders and discussed some of the difficulties in predicting the failure of such structures [13]. It appears that the most reliable way to evaluate composite cylinders today is to run hydrostatic pressure tests, but these are expensive and require specialised equipment.

Thermoplastic composites are not necessarily well-suited to resist compression loading. Much early work for aeronautical applications was aimed at understanding why low values were obtained in tests on unidirectionally reinforced thermoplastic composites [14,15]. Fibre waviness, porosity and internal stresses have all been shown to be important. However, in the DARPA project waviness and porosity were both carefully monitored and it was demonstrated that excellent compression performance could be achieved $[6,16]$.

The present work was initiated in order to establish whether thermoplastics offered significant advantages over the filament wound glass/epoxy materials currently employed for deep sea oceanographic containers. These are small cylinders used to protect instrumentation or electronic equipment deployed in the ocean to measure physical parameters of the deep sea environment. Figure 1 shows two examples. The reference material for evaluation of the thermoplastics is therefore an E-glass reinforced $125^{\circ} \mathrm{C}$ cure epoxy system.

\section{Figure 1. Deep sea instrumentation containers}

There are many other underwater applications where the low weight and good corrosion resistance of composites are attractive. These include underwater vehicles; the AUSS [17] and AUTOSUB [18] projects are examples where composites were employed for the main hull structure, and composites are also used on secondary structures of other deep sea submersibles such as the IFREMER manned 6000 meter depth submersible Nautile. There are many composite components on military submarines including sonar domes and outer decks $[19,20]$. The offshore industry has also developed a number of large composite structures such as risers $[21,22]$. These are currently being tested in sea trials and could result in the use of 
very significant quantities of composites. Sub-sea equipment may provide further opportunities in this sector [23]. So far all of these applications are based on thermoset matrix composites, mainly epoxies. The present work may also be useful in evaluating the potential of thermoplastic composites to replace these, though the larger scale of such structures will introduce additional manufacturing parameters.

In this paper results from preliminary screening tests on six candidate thermoplastic composite materials will be given first. Based on these results glass/PEI and carbon/PEEK materials were selected for further evaluation. Cylindrical structures were manufactured and subjected to implosion tests. Finally impact behaviour and residual implosion resistance after impact of the carbon/PEEK cylinders are presented and compared with results for carbon/epoxy of similar geometry.

\section{SCREENING TESTS}

\section{Materials}

There are many combinations of fibres and thermoplastic matrix materials on the market, with a range of properties and prices. A first selection of promising materials was made and Table 1 shows the materials tested, but it should be emphasised that this list is certainly not exhaustive. The samples which were available for initial evaluation were in the form of flat, mostly unidirectionally reinforced panels, of dimensions $200 \mathrm{~mm}$ by $300 \mathrm{~mm}$. It was recognised that tests on such specimens could only be used to give a first indication of the suitability of the material for marine applications. This enabled material limitations to be identified at an early stage but it is appreciated that the manufacture of structures could introduce many other factors (waviness, porosity...) which could dominate the final selection. Unfortunately hydrostatic pressure tests were too costly and time consuming for the present project to allow the final evaluation of more than two different materials.

\section{Table 1. Materials retained for screening tests}

The glass and carbon/epoxy reference materials were produced by wet winding unidirectional layers and compression moulding in a press followed by oven curing.

The glass/polypropylene (PP) and carbon/PEEK were compression moulded from prepreg, Results for these materials were obtained in two previous studies [24,25]. 
The polyamide (PA), polyetherimide (PEI ) and poly (phenylene sulfide), (PPS) composites were prepared by powder impregnation of strips followed by compression moulding in a hot press.

\section{Screening tests on flat specimens}

Each material was first analysed to determine fibre volume fraction (by calcination for glass, density or acid digestion for carbon composites), and glass transition temperature (TA Instruments DMA 2980, in three point flexure on $10 \mathrm{~mm}$ x $60 \mathrm{~mm}$ specimens, $1 \mathrm{~Hz}$ loading frequency, heating rate $5^{\circ} \mathrm{C} /$ minute).

Two simple standard mechanical tests were retained for screening purposes, three point flexure (span to thickness ratio $1 / \mathrm{h}$ of 16 for glass and 40 for carbon composites), to examine whether compression failure occurred, and short beam shear $(1 / \mathrm{h}$ of 5$)$, to measure apparent interlaminar shear behaviour. These tests were performed dry and after periods of wet ageing. Given the small quantities of material available only two or three specimens were tested in flexure and five in short beam shear. Table 1 shows the mean results from the tests on nonaged specimens. The flexural modulus values are consistent with the fibre contents. Flexural strengths are around $1000 \mathrm{MPa}$ for all the materials except the PP which had a low fibre volume fraction. The PA and PEI fail in compression, the PPS composites fail by delamination. Interlaminar shear strength is often used as a quality control test. Values for the PEI composites are very high. The PA tends to show crushing failure rather than delamination, while the PPS composites delaminate very easily. Based on these values the glass/PEI composite appears very promising compared to the glass/epoxy currently used.

\section{Wet Aging}

Wet aging tests on glass/PP in water at $50^{\circ} \mathrm{C}$ were reported previously [24] and it was shown that the microstructure depended on the cooling rate during manufacture and this strongly influenced weight gain during aging. A two year aging of XAS carbon reinforced PEEK at various temperatures up to $60^{\circ} \mathrm{C}$ in distilled water [25] showed no significant evolution of the properties of this material.

Specimens of PA, PEI and PPS composites were cut to size for flexure and ILSS tests, dried in an oven at $50^{\circ} \mathrm{C}$ and then placed in a water bath containing natural sea water at $60^{\circ} \mathrm{C}$. Square $50 \mathrm{~mm}$ by $50 \mathrm{~mm}$ samples were also immersed and weighed regularly on a Sartorius balance. Weight gains were recorded and specimens were removed for testing after different immersion periods. 
The use of narrow specimens rather than large plates may influence the weight gains, but the comparison of weight gains for different specimen widths does not show a large effect here, Figure $2 \mathrm{a}$. Figure $2 \mathrm{~b}$ shows a comparison of the weight gains of the $50 \mathrm{x} 50 \mathrm{~mm}^{2}$ samples of all the glass reinforced composites and carbon/PA12 aged at $60^{\circ} \mathrm{C}$. The PEI and the carbon/PA saturate at low weight gain values, while the glass/PA and PPS composite samples continue to increase in weight after 3 months' immersion.

Fig 2 Weight gain plots, a) glass/PEI, b) all composites

Figure 3 shows the flexural strength results from these tests. All the strength values tend to decrease with aging. Significant drops are measured for the PA and PPS composites, while the PEI strength loss is less than $10 \%$ after 3 months' immersion.

Figure 3. Influence of aging on mean flexural strength values, error bars show minimum and maximum values

Figure 4 shows the interlaminar shear strengths obtained after aging. Again the PEI composites show less sensitivity to water immersion than the PA and PPS composites.

Figure 4. Influence of aging on mean ILSS values, error bars show \pm one standard deviation.

These tests revealed that prolonged exposure to water may affect the polyamide matrix properties, albeit in a reversible way. It is also apparent that this glass/PPS composite system is very sensitive to water, in this case the fibre/matrix interface is clearly not optimised for this application and degrades irreversibly. Pomiès found similar results for another glass/PPS composite immersed in sea water for 7 months at $35^{\circ} \mathrm{C}$ [9] while Juska found better strength retention in carbon/PPS composites after 9 months at $50^{\circ} \mathrm{C}[10]$. The glass/PEI system tested here showed no sensitivity to water. For comparison there have been several previous studies of the aging of the glass/epoxy composite [26,27]. The anhydride hardener employed leads to a resin which is susceptible to hydrolysis in water at $60^{\circ} \mathrm{C}$ but at lower temperatures it shows good durability.

The results from screening tests such as these must be treated with caution for several reasons. First, the materials and processing routes employed for the preliminary screening tests may not be exactly those that will be used to produce structural parts. It would certainly be 
preferable to test cylinders directly, but these were not available at the start of the test programme. Second, the tests are quite severe, full immersion of thin specimens at $60^{\circ} \mathrm{C}$ does not simulate the response of a thick composite exposed to water in deep sea at less than $10^{\circ} \mathrm{C}$ on one side only. Thirdly the numbers of specimens tested are quite small. Nevertheless, based on the results two materials were selected for further evaluation, glass/PEI and carbon/PEEK. Samples of tubes were therefore produced.

\section{TESTS ON CYLINDERS}

\section{Materials}

Cylinders of both materials were produced by tape laying. The first layer on the mandrel is at $90^{\circ}$, all subsequent layers are at $\pm 55^{\circ}$ with respect to the tube axis. This angle is not optimal for external pressure resistance, $0 / 90_{2}{ }^{\circ}$ should perform better, but the $\pm 55^{\circ}$ sequence is widely available and allowed a direct comparison with the glass and carbon/epoxy tubes currently used. The manufacturing process involves local heating and compaction using a special gas heater [28].

The reinforcement of the PEI was S2 glass fibres, and cylinders were of inner diameter $175 \mathrm{~mm}$ and wall thickness $20 \mathrm{~mm}$. Fibre content was nominally $57 \%$ by volume.

AS4 carbon fibres were used to reinforce the PEEK cylinders, which were smaller than the glass/PEI, $55 \mathrm{~mm}$ inner diameter and $6.5 \mathrm{~mm}$ thick. Fibre content was nominally $61 \%$ by volume.

Two thermoset matrix reinforced composite cylinders of similar geometry to the thermoplastics and the same fibre orientation were used for comparison, produced by wet winding. These are E-glass and T700 carbon reinforced epoxy LY556/HY905 resin. Both were cured at $125^{\circ} \mathrm{C}$, fibre contents are 62 and $66 \%$ by volume.

\section{Quality control tests on cylinders}

All the cylinders tested in this study were controlled on reception by ultrasonic C-scan in the transmission mode, using 2 and $5 \mathrm{MHz}$ focussed transducers. A Sofratest ultrasonic inspection system was used to measure through-thickness attenuation, by placing the cylinders on a rotating table in a water tank. This enabled a problem with the PEI cylinders to be identified rapidly, as the ultrasonic signal was completely attenuated. For similar glass/epoxy cylinders attenuation was below $15 \mathrm{~dB}$. 
The attenuation level used for accepting the carbon reinforced cylinders was the same as that employed in previous studies for carbon/epoxy tubes, namely a $25 \mathrm{~dB}$ attenuation. The value of this criterion is based on experience and it cannot be used alone to define tube quality. Olson et al have shown that while high attenuation levels can be related to high porosity in thermoplastic composite cylinders there is not a simple relationship between $\mathrm{dB}$ loss and porosity level below 2\% [16]. Examples of C-scans for carbon/PEEK and carbon/epoxy cylinders are shown in Figure 5. The attenuation levels were similar for both.

Figure 5. Examples of ultrasonic C-scan maps, $2 \mathrm{MHz}$ focussed transducer, C/PEEK and C/Epoxy.

A simple mechanical test was then employed to evaluate the mechanical performance. This was intended to provide quality control information, so that future material systems may be evaluated rapidly before proceeding to costly implosion tests in pressure vessels. They are performed on ring segments, as shown in Figure 6, This test, described in ASTM 2344-1984, yields an apparent interlaminar shear strength. Figure 6 shows the results for both materials, together with results from tests on the glass and carbon reinforced epoxy samples from cylinders of similar diameters.

Figure 6. Apparent interlaminar shear strength tests, insert photo shows specimen during test

The results from these tests suggested that the fabrication of the glass/PEI tubes was not optimised. A large quantity of small defects throughout the wall thickness were noted, Figure 7.

Figure 7. Defects in glass/PEI cylinder wall

The results for the carbon/PEEK specimen are similar to those of the carbon/epoxy system, suggesting a reasonable fabrication quality. Sections through the carbon/PEEK tube wall indicated low void content and little fibre waviness, Figure 8.

Figure 8. Section through carbon/PEEK cylinder wall cut at $55^{\circ}$ to tube axis. 


\section{Hydrostatic pressure tests}

Implosion tests were performed at the IFREMER pressure test facility in Brest in a 2400 bar pressure vessel, Figure 9.

Figure 9. 2400 bar pressure vessel used for implosion tests

All specimen lengths were twice the inner diameters. The glass reinforced cylinders were 350 $\mathrm{mm}$ long, carbon fibre cylinders were $110 \mathrm{~mm}$ long. Cylinder ends were machined to ensure they were parallel. The end closures are critical in these tests on thick cylinders as stress concentrations can provoke premature collapse [29,30]. Aluminium end closures were used to close the large diameter cylinders [31]. These have contoured plugs to provide a progressive contact with the inner wall as pressure is increased. Figure 10a shows the glass/PEI specimen before implosion. Machined aluminium end caps were bonded to the small diameter cylinder ends, Figure 10b, these were designed to avoid fiber brooming, and these cylinders were placed between rigid end blocks. Previous tests on small and large diameter carbon/epoxy cylinders have yielded similar results using the two end closure systems [32].

Figure 10. Experimental fixtures for implosion tests.

Cylinders were partially filled with oil to reduce the shock wave at implosion. Pressure was increased at a ramp rate of 12 bars/minute until failure. In order to compare results from cylinders with slightly different measured wall thickness a nominal hoop stress at implosion is also used. This is calculated as :

$$
\sigma_{\theta \theta}=\operatorname{Pr} / \mathrm{t}
$$

with $\mathrm{P}$ the pressure in $\mathrm{MPa}, \mathrm{r}$ the mean radius and $\mathrm{t}$ the wall thickness. For the large diameter glass reinforced cylinders 18 biaxial hoop/axial strain gages were placed inside the cylinder. Twelve were placed around the mid section in order to determine whether buckling occurred, the others were placed along the tube and near the ends to check for stress concentrations. Examples can be seen in Figure 10a. For most of the small diameter carbon reinforced tubes only pressure versus time was recorded as the limited space available makes it more difficult to bond strain gauges. However in one epoxy and one PEEK cylinder two hoop strain gauges were bonded at mid-height, separated by $90^{\circ}$. Table 2 shows the cylinders tested and the results. 


\section{Implosion results for glass reinforced composite cylinders}

The reference glass/epoxy cylinders, $175 \mathrm{~mm}$ diameter, imploded at pressures around 900 bars (90 MPa). The glass/PEI cylinder imploded at a much lower pressure, around 400 bars (40 $\mathrm{MPa}$ ). Figure 11 shows examples of strain measurements at the inner wall during pressure loading for the two cylinders. The hoop strains at the tube end are very similar to those measured in the centre while axial strains tend to be lower near the end caps. Strains in the glass/epoxy cylinder reach $1.5 \%$ before failure whereas the glass/PEI fails at much lower midsection strains. There is also considerable scatter in the strains measured on the latter.

Figure 11. Examples of axial and hoop strain response from 28 strain gauges, 24 at centre and 2 at each end of cylinder a) glass/epoxy and b) glass/PEI.

Figure 12 shows all the central hoop strain recordings at different pressures.

Figure 12. Pressure versus central inner wall hoop strains for all gauges,

a) glass/epoxy and b) glass/PEI.

The lower failure of the glass/PEI compared to the glass/epoxy appears to be caused by a local buckling failure mode. There is no evidence of global buckling for either of the cylinders. Figure 13 shows cylinders after implosion. There is a small region of the glass/PEI tube which has imploded. This is quite different to the more global crushing failure mode observed for thick glass/epoxy cylinders.

\section{Figure 13. Cylinders after implosion a) glass/PEI, b) glass/epoxy}

The reason for the poor performance of this thermoplastic composite material appears to be the presence of the defects shown in Figure 7. Given the excellent performance of this material in screening tests further work is needed to optimise the manufacture of cylindrical structures, in order to realise its full potential. For the glass/epoxy no sign of buckling was detected by strain gages. The failure values obtained are slightly lower than those published by Hinton for a similar material [13] but the geometry is not identical as those authors tested 
smaller cylinders. Tests on $55 \mathrm{~mm}$ diameter glass cylinders resulted in higher values, up to 1340 bars (134 MPa).

\section{Implosion results for carbon reinforced composite cylinders}

Two undamaged $55 \mathrm{~mm}$ diameter cylinders were imploded for each material. Failure pressures of 105 and $117.5 \mathrm{MPa}$ for the C/epoxy and 89 and $94 \mathrm{MPa}$ for the C/PEEK were measured. The cylinders after testing are shown in Figure 14.

Figure 14. Cylinders after testing a) carbon/PEEK, b) carbon/epoxy

In both cases the cylinders imploded completely with no sign of a buckling failure. The two strain gages placed at $90^{\circ}$ on the inner wall of the tubes indicated very similar values and linear readings up to failure, Figure 15.

Figure 15. Strain gauge readings, inner wall a) carbon/PEEK, b) carbon/epoxy cylinders.

These results show that the compression resistance of the carbon/PEEK composite in the configuration tested here is sufficient to envisage its use at depths down to 6000 metres (with a safety factor of 1.5). This is very encouraging, but if a clear advantage over the carbon/epoxy option is to be demonstrated then the damage tolerance behaviour must also be studied. The glass/PEI cylinders were not studied further here but an impact study was performed on the carbon/PEEK cylinders.

\section{DAMAGE TOLERANCE OF CYLINDERS}

\section{Impact resistance}

Carbon/PEEK and carbon/epoxy cylinders were placed in a cradle and subjected to a single central impact by a weight of $1.6 \mathrm{~kg}$ with a $50 \mathrm{~mm}$ diameter hemispherical steel end. The impacter is guided by a slider running down a rail. Three drop heights were used, 0.5, 1 and 1.5 meters, as preliminary tests had shown that these produced significant levels of damage. A spring released clamp activated by an electromagnet was used to catch the impacter to avoid rebound impacts. Impact energy was determined as $1 / 2 \mathrm{mv}^{2}$, with $\mathrm{m}$ the mass and $\mathrm{v}$ the speed. The latter was measured by two photocells just before impact, rather than using potential 
energy (mgh), as there is a small loss in energy (around 10\%) due to friction between the slider and the rail. Figure 16 shows the impact set-up.

Figure 16. Drop weight impact set-up

Each cylinder was C-scanned before impact. After impact the damage introduced was identified by two methods, first ultrasonic C-scan and then sectioning. A focalised $2 \mathrm{MHz}$ transducer was used. This enabled clear damage regions to be defined, Figure 17, and the areas of these are plotted in Figure 18.

Figure 17. Damaged area detected by ultrasonic C-scan

Figure 18. Projected damage area versus impact energy

It is apparent that these energy levels result in much smaller projected damage areas in the thermoplastic composite than in the carbon/epoxy cylinders. Similar results have been reported previously $[33,34]$.

Cylinders impacted at each energy level were then sectioned in the axial and circumferential directions and polished. A fluorescent dye was allowed to soak into the surface for 4 hours before re-polishing the surface. This enabled the impact damage to be visualised under an ultraviolet lamp. Figure 19 shows examples of the damage detected. The carbon/epoxy delaminates at all the interfaces between covers (a cover is a $\pm 55^{\circ}$ layer) and a very clear damage zone can be identified in the hoop direction. In the axial direction there is also delamination but with more intraply cracking. The damage in the thermoplastic composite is less easy to visualise but there are some delaminations and small cracks.

Figure 19. Sections of cylinders showing impact damage in the axial and hoop directions

\section{Residual implosion pressure after impact}

After impact three carbon/epoxy and three carbon/PEEK cylinders were subjected to hydrostatic pressure tests in order to determine their residual implosion pressure. Figure 20 shows the results from these tests.

Figure 19. Residual implosion pressure versus impact energy 
It is surprising to note that in spite of the excellent intrinsic toughness of the carbon/PEEK system [33,35] there is a stronger drop-off in implosion pressure after impact for the thermoplastic composite than for the carbon/epoxy. Examination of the C/PEEK cylinders after implosion indicated that premature buckling had been initiated by the impact damaged regions, Figure 21. This is quite different to the crushing mode seen in Figure 14, whereas the crushing failure mode of the epoxy cylinder remained unchanged after impact.

Figure 20. Examples of impacted cylinders after implosion, a) carbon/PEEK, b) carbon/epoxy

This comparison with the results for the epoxy composite is not straightforward as there are several differences between the two sets of cylinders. First, the fibres are not identical, the T700 fibre in the epoxy has a higher tensile strain to failure than the AS4 fibre. In addition the fibre contents are not identical and the epoxy cylinders are stiffer in the hoop direction than the thermoplastic composite cylinders. This hoop stiffness is critical for buckling and a direct comparison using the same fibres and fibre volume fraction would certainly be preferable, but such materials were not available for this study. Finally, it should be pointed out that the two fabrication methods also result in a significant difference in the fibre architecture obtained. The tape placement method results in low fibre waviness while the wet winding produces a woven structure within each $\pm 55^{\circ}$ cover and potentially damaging cross-over points. The residual stress state will also be affected by the fabrication parameters, which were not studied here. Nevertheless the comparison presented here is of interest as these are two commercially available cylinders with the same geometry intended for the same underwater application.

These results raise a number of questions concerning the transfer of toughness from materials to structures. Correlations have been made in the past between mode II fracture toughness $\mathrm{G}_{\text {IIc }}$ and impact damage in cylinders, e.g. [36], and between $\mathrm{G}_{\text {IIc }}$ and residual compression strength after impact of flat panels [37], but there are many factors which can influence this correlation. Efforts have been made recently to use specimens cut from cylinders to measure $\mathrm{G}_{\text {IIc }}$ in order to reduce the influence of fabrication parameters. This may clarify the toughness transfer, but it requires films to be implanted during fabrication [38]. Further work is needed to explain the implosion after impact behaviour observed here. 


\section{CONCLUSIONS}

This paper presents results from a series of tests performed on thermoplastic matrix composites, in order to select materials for more extensive testing for underwater applications. Results from screening tests to determine mechanical properties and sensitivity to water suggested that glass/PEI and carbon/PEEK composites are the most promising materials for further study. Cylinders were therefore manufactured in these two materials. Quality control tests on specimens cut from these cylinders indicate that the properties of the former may not achieve those predicted from flat specimens and implosion occurred at a much lower hydrostatic pressure than the glass/epoxy reference material. The carbon/PEEK cylinder imploded at a pressure above $90 \mathrm{MPa}$ and appears more promising for these applications. However, its residual implosion resistance after impact decreased more quickly than that of a carbon/epoxy cylinder of equivalent geometry, suggesting further work is needed to ensure the transfer of material toughness into structural damage tolerance. Further work is now underway to examine the influence of winding angle, in particular $0 / 90_{2}{ }^{\circ}$ rather than $\pm 55^{\circ}$, in order to optimise cylinder performance.

\section{Acknowledgements}

The assistance of David Leach, of Cytec Engineered Materials, with the carbon/PEEK cylinder supply, is gratefully acknowledged. 


\section{References}

[1] Cogswell FN, Thermoplastic aromatic polymer composites, 1992, Woodhead Publishing.

[2] Carlsson LA, Editor, Thermoplastic Composite Materials, Composite Materials Vol 7, Elsevier, 1991.

[3] Kausch HH Editor, Advanced Thermoplastic Composites, Hanser Publications, 1993.

[4] Sharp R, Holmes S, Woodall C, Material Selection/fabrication issues for thermoplastic fiber placement, J. Thermoplastic Composite Materials, 1995, Vol 8, January, pp2-14.

[5] Lamontia MA, Gruber MB, Smoot MA, Sloan J, Gillespie JW Jr., Performance of a filament wound graphite/thermoplastic composite ring stiffened pressure hull model, J. Thermoplastic Composite Materials, 1995, Vol 8, January, pp15-36.

[6] Gruber MB, Lamontia MA, Smoot MA, Peros V, Buckling performance of hydrostatic compression loaded 7-inch diameter thermoplastic composite monocoque cylinders, J. Thermoplastic Composite Materials, 1995, Vol 8, January, pp94-108.

[7] Lamontia MA, Funck SB, Gruber MB, Cope RD, Waibel BJ, Gopez NM, Manufacturing Flat and Cylindrical laminates and built up structures using automated thermoplastic tape laying, fiber placement and filament winding, SAMPE Journal, 39, 2, March 2003, pp30-38.

[8] Demonet CM, Interaction of moisture with resin matrix composites, Proc $21^{\text {st }} \mathrm{SAMPE}$ Tech. Conf., Sept. 1989, p231-238.

[9] Pomiès F, Carlsson LA, Gillespie JW Jr, Marine Environmental effects on polymer matrix composites, in ASTM STP 1230, 1995.

[10] Juska T, Effect of water immersion on fiber/matrix adhesion in thermoplastic composites, US Navy report Carderockdiv-SSM-64-93/02, March 1993.

[11] Weitsman YJ, Effects of fluids on polymeric composites-A Review, University of Tennessee report MAES98-5.0-CM, August 1998.

[12] AFNOR standard XP X 10-812, Marine environment, oceanographic equipment, environmental test and recommendations for test equipment 1995.

[13] Soden PD, Hinton MJ, Kaddour AS, Biaxial test results for strength and deformation of a range of E-glass and carbon fibre reinforced composite laminates, Comp. Sci \& Tech., 62, 2002, pp1489-1514.

[14] Leach DC, Continuous Fibre reinforced thermoplastic matrix composites, Chapter 2 in Advanced Composites, Editor IK Partridge, Elsevier 1989, p43-109.

[15] Lee RJ, Compression strength of aligned carbon fibre reinforced thermoplastic laminates, Composites, 18, 1, January 1987. 
[16] Olson BD, Lamontia MA, Gillespie JW Jr., Bogetti TA, The effects and non destructive evaluation of defects in thermoplastic compression loaded composite cylinders, J. Thermoplastic Composite Materials, 1995, Vol 8, January, pp109-136.

[17] Stachiw JD, Frame B, Graphite fiber reinforced plastic pressure hull mod 2 for the advanced unmanned search system vehicle, Tech Report 1245, Naval Ocean Systems Center, San Diego, 1988.

[18] Stevenson P, Graham D, Clayson C, The mechanical design and implementation of an autonomous submersible, J. Soc. For Underwater Technology, 23, 1, 1998 pp31-41.

[19] Lemière Y, The evolution of composite materials in submarine structures, in Proc. $3^{\text {rd }}$ Conference on Nautical Construction in Composite Materials, Ifremer press, 1992, pp441449.

[20] Mouritz A, Gellert E, Burchill P, Challis K, Review of advanced composite structures for naval ships and submarines, Comp. Struct., 53, 2001, 21-41.

[21] Storhaug T, Significant achievements in composite technology in 2001; Qualification and testing of Composite tethers and risers for Ultra seep water, Proc. Deep offshore Technology, DOT 2001, Rio de Janeiro, October 2001

[22] Salama MM, Storhaug T, Spencer B, Recent developments of composites in the Oil/Gas Industry, SAMPE journal, 38, 1, Jan/Feb 2002, p30.

[23] Bigourdan BB, Chauchot P, Astrugue JC, Alary V, Dilosquer S, Falcimaigne J, Rigaill C, Gerard P, Composite Materials for Subsea Oil production, Proc. Deep Offshore Technology, DOT 2003, Marseille.

[24] Davies P, Cantwell WJ, Fracture of glass/polypropylene laminates, Composites, 25, 9, 1994, pp869-877.

[25] Choqueuse D, Davies P, Mazéas F, Baizeau R, Aging of composites in water, ASTM STP 1302, 1997, pp73-96.

[26] Davies P, Choqueuse D, Mazeas F, Composites Underwater, Proc. DURACOSYS, 1998, Balkema, 19-24

[27] Davies P, Baizeau R, Choqueuse D, Salmon L, Nagot F, Aging and long term behaviour of composite tubes, Proc DURACOSYS 2000, Balkema, 143-152.

[28] Mondo J, Langone R, Quinn L, Composites for downhole applications at $300^{\circ} \mathrm{F}$ and above, Proc. $3^{\text {rd }}$ Oilfield Engineering with Polymers conference, Rapra, 28-29 Nov. 2001, London, p113-124.

[29] Blake HW, Starbuck JM, A shear deflection theory for analysis of end plugs for external pressure tests of composite cylinders, ASTM STP 1185, 1994, p113-136. 
[30] Yousefpour A, Ghasemi Nejhad MN, Effects of geometric optimization of plug supported end-caps on the performance of thick thermoplastic composite pressure vessels under external hydrostatic pressure, J. Thermoplastic Cop., 2002, 15 (5), p403-428.

[31] Davies P, Le Flour D, Proc. $3^{\text {rd }}$ Oilfield Engineering with Polymers conference, RAPRA, 28-29 Nov. 2001, London, p255-268.

[32] Davies P, Scale and size effects in the mechanical characterization of composite and sandwich materials, Proc. ICCM12, July 1999, Paris.

[33] Leach DC, Moore DR, Toughness of aromatic polymer composites reinforced with carbon fibres, Comp. Science and Technology, 23, 2, 1985, pp 131-161.

[34] Ishikawa T, Sugimoto S, Matsushima M, Hayashi Y, Some experimental findings in compression-after-impact (CAI) tests of CF/PEEK (APC2) and conventional CF/Epoxy flat plates, Comp. Sci \& Tech., 55, 1995, 349-363.

[35] Gillespie JW Jr, Carlsson LA, Buckling and growth of delamination in thermoset and thermoplastic composites, Trans. ASME, J. Eng Mats and Technology, Jan 1991, 113, pp9398.

[36] Gning PB, Tarfaoui M, Collombet F, Davies P., Prediction of damage in composite tubes after impact, Proc ICCM14, San Diego, July 2003.

[37] Masters JE, Correlation of impact and delamination resistance in interleafed laminates, Proc. ICCM6, London, July 1987, Elsevier, 3.96.

[38] Ozdil F, Carlsson LA, Davies P, Beam analysis of angle ply laminate end-notched flexure specimens, Comp. Sci \& Tech., 1998, 58, 1929-38. 


\begin{tabular}{cccccccc}
\hline Composite & Fibers & $\begin{array}{c}\mathrm{Vf} \\
\%\end{array}$ & $\begin{array}{c}\mathrm{t} \\
\mathrm{mm}\end{array}$ & $\begin{array}{c}\mathrm{Tg} \\
{ }^{\circ} \mathrm{C}\end{array}$ & $\begin{array}{c}\mathrm{E}_{1 \mathrm{f}}, \\
\mathrm{GPa}\end{array}$ & $\begin{array}{c}\text { Flexural } \\
\text { strength } \\
\sigma_{1 \mathrm{f}}, \mathrm{MPa}\end{array}$ & $\begin{array}{c}\text { ILSS } \\
\mathrm{MPa}\end{array}$ \\
\hline Glass/Epoxy & E Glass & 52 & 4 & 110 & 45 & 1200 & 62 \\
Glass/PP Ref. [24] & E Glass & 35 & 4 & - & 25 & 450 & 33 \\
Glass/PA12 & E Glass & 45 & 3 & 40 & 44 & 840 & 45 \\
Glass/PPS & S2 Glass & 45 & 3.2 & 110 & 47 & 1145 & 28 \\
Glass/PEI & S2 Glass & 40 & 3.2 & 220 & 35 & 950 & 77 \\
Carbon/Epoxy & T700 & 52 & 3 & 120 & 98 & 1265 & 74 \\
Carbon/PA12 & 34700 & 45 & 2 & 40 & 122 & 1100 & 39 \\
Carbon/PEEK & XAS & 55 & 3.3 & 145 & 54 & 820 & 82 \\
0/90Ref. [25] & & & & & & & \\
\hline
\end{tabular}

Table 1. Composites studied and measured dry properties.

All flat unidirectional specimens except C/PEEK.

\begin{tabular}{ccccc}
\hline Material & $\begin{array}{c}\text { Inner Diameter } \\
\mathrm{mm}\end{array}$ & $\begin{array}{c}\text { Wall thickness } \\
\mathrm{mm}\end{array}$ & $\begin{array}{c}\mathrm{t} / \mathrm{R}_{\text {mean }} \\
\text { ratio }\end{array}$ & $\begin{array}{c}\text { Nominal } \sigma_{\theta \theta} \text { at } \\
\text { implosion, } \mathrm{MPa}\end{array}$ \\
\hline E glass/epoxy & 55 & 6.5 & 0.19 & 701 \\
E glass/epoxy & 175 & 19 & 0.18 & 523 \\
\hline S2 glass/PEI & 175 & 20 & 0.19 & 214 \\
\hline T700/epoxy & 55 & 6.5 & 0.19 & 615 \\
T700/epoxy & 175 & 18 & 0.17 & 572 \\
\hline AS4/PEEK & 54 & 6.4 & 0.19 & 504
\end{tabular}

Table 2. Cylinders tested under hydrostatic pressure 


\section{LIST OF FIGURE HEADINGS}

Figure 1. Deep sea instrumentation containers in glass/epoxy composite.

a) $55 \mathrm{~mm}$ inner diameter messenger tubes, b) $150 \mathrm{~mm}$ inner diameter instrumentation containers

Figure 2 Weight gain plots in \%, a) PEI, different sample sizes b) all composites $50 \times 50 \mathrm{~mm}^{2}$ plaques

Figure 3. Influence of aging on mean flexural strength values, error bars show minimum and maximum values.

Figure 4. Influence of aging on mean ILSS values, error bars show \pm one standard deviation.

Figure 5. Examples of ultrasonic C-scan maps, $2 \mathrm{MHz}$ focussed transducer, C/PEEK and

C/Epoxy.

Figure 6. Apparent interlaminar shear strength tests, curved specimens, error bars show \pm one standard deviation insert photo shows specimen of glass/PEI during test

Figure 7. Defects in glass/PEI cylinder wall

Figure 8 . Section through carbon/PEEK cylinder wall cut at $55^{\circ}$.

Figure 9. 2400 bar pressure vessel used for implosion tests, showing $175 \mathrm{~mm}$ diameter glass/epoxy cylinder before test.

Figure 10. Experimental fixtures for implosion tests.

Figure 11. Examples of axial and hoop strain response from 28 strain gauges, 24 at centre and 2 at each end of cylinder a) glass/epoxy and b) glass/PEI.

Figure 12. Central section inner wall hoop strains, a), glass/epoxy and b) glass/PEI.

Figure 13. Cylinders after implosion a) glass/epoxy, b) glass/PEI

Figure 14. Cylinders after implosion a) carbon/epoxy, b) carbon/PEEK

Figure 15. Hoop strain gauge readings, inner wall, mid-height

a) carbon/PEEK, b) carbon/epoxy cylinders.

Figure 16. Drop weight impact set-up.

Figure 17. Damaged areas detected by ultrasonic C-scan.

Each photo represents an $80 \mathrm{~mm} \times 80 \mathrm{~mm}$ area.

Figure 18. Projected damage area versus impact energy

Figure 19. Polished sections of cylinders with dye penetrant showing impact damage in the axial and hoop directions, one meter drop height

Figure 20. Residual implosion pressure versus impact energy

Figure 21. Examples of impacted cylinders after implosion

a) $\mathrm{C} / \mathrm{PEEK}$, b) C/Epoxy 


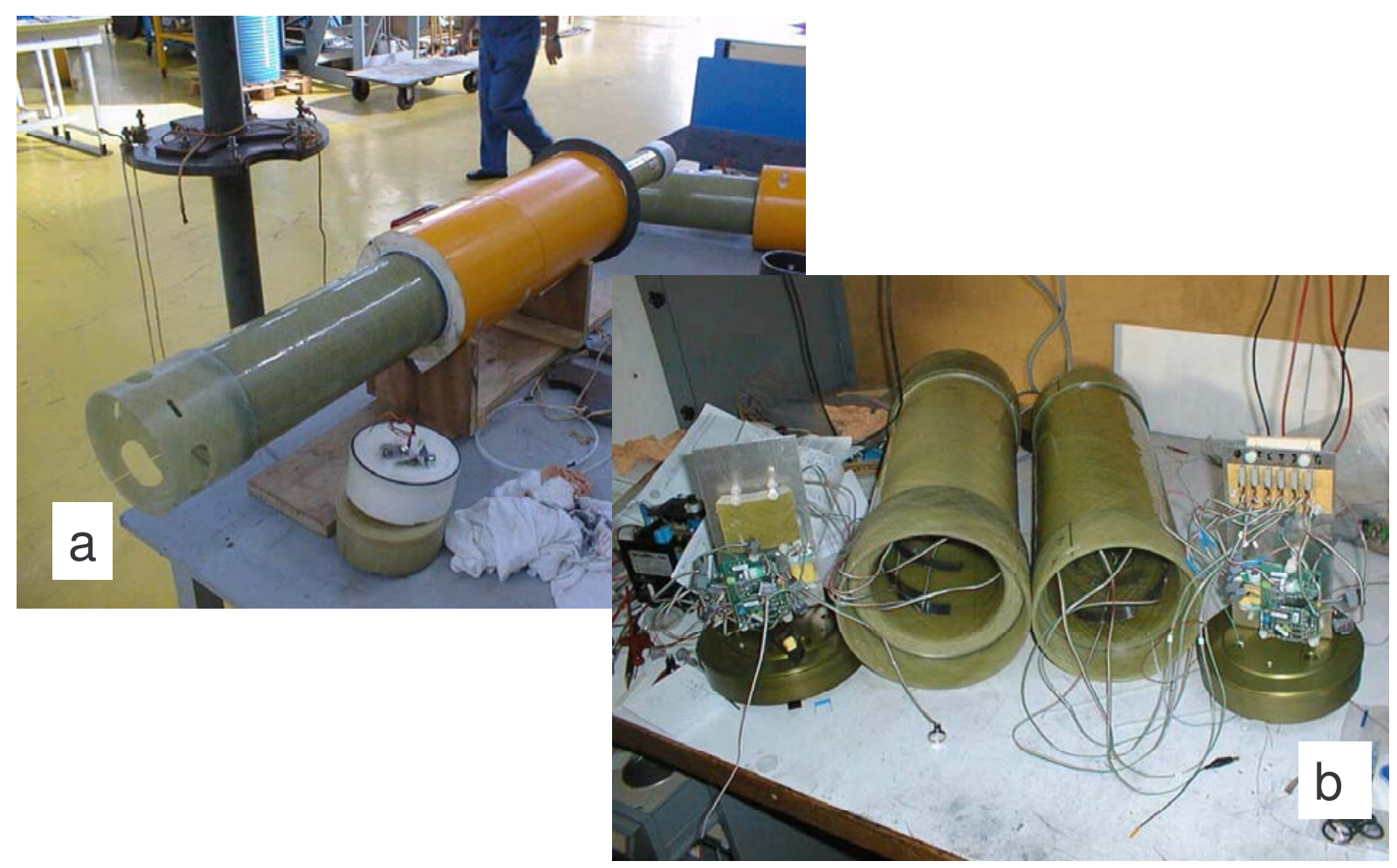

Figure 1. Deep sea instrumentation containers in glass/epoxy composite.

a) $55 \mathrm{~mm}$ inner diameter messenger tubes, b) $150 \mathrm{~mm}$ inner diameter instrumentation containers 
a) Glass/PEI $60^{\circ} \mathrm{C}$ sea water

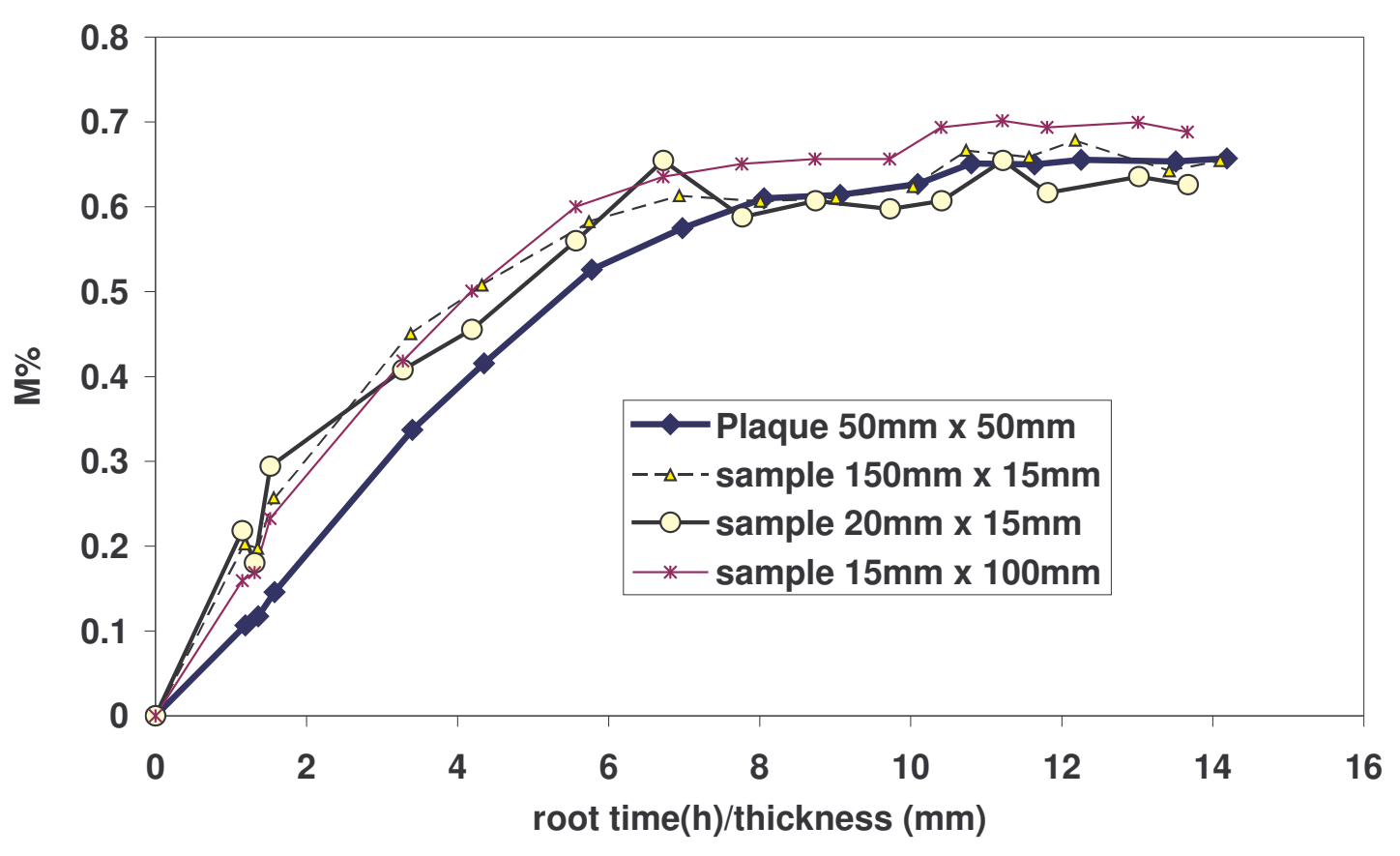

b) Immersion $60^{\circ} \mathrm{C}$ sea water

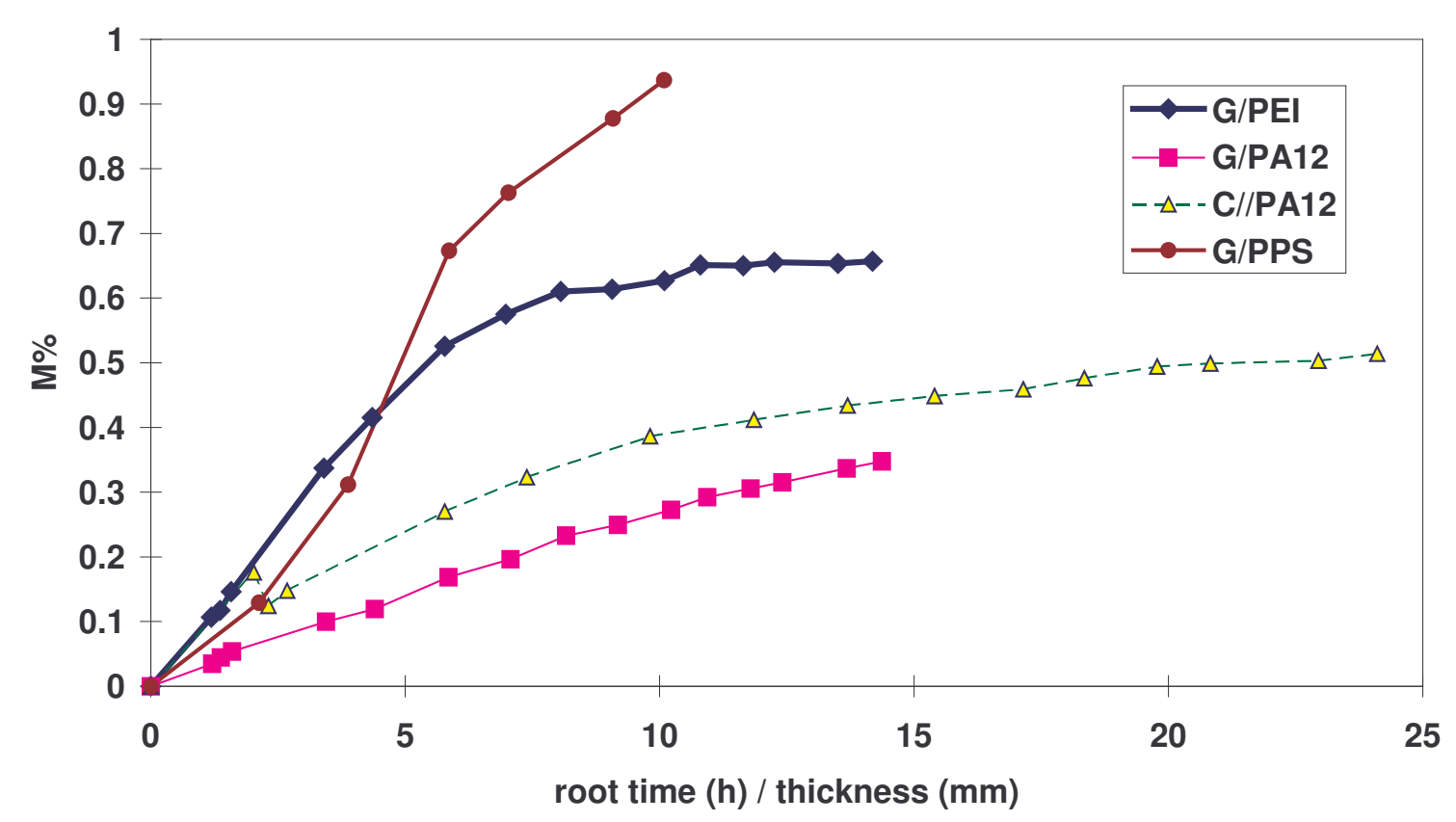

Figure 2 Weight gain plots in \%, a) PEI, different sample sizes b) all composites 50 x $50 \mathrm{~mm}^{2}$ plaques 


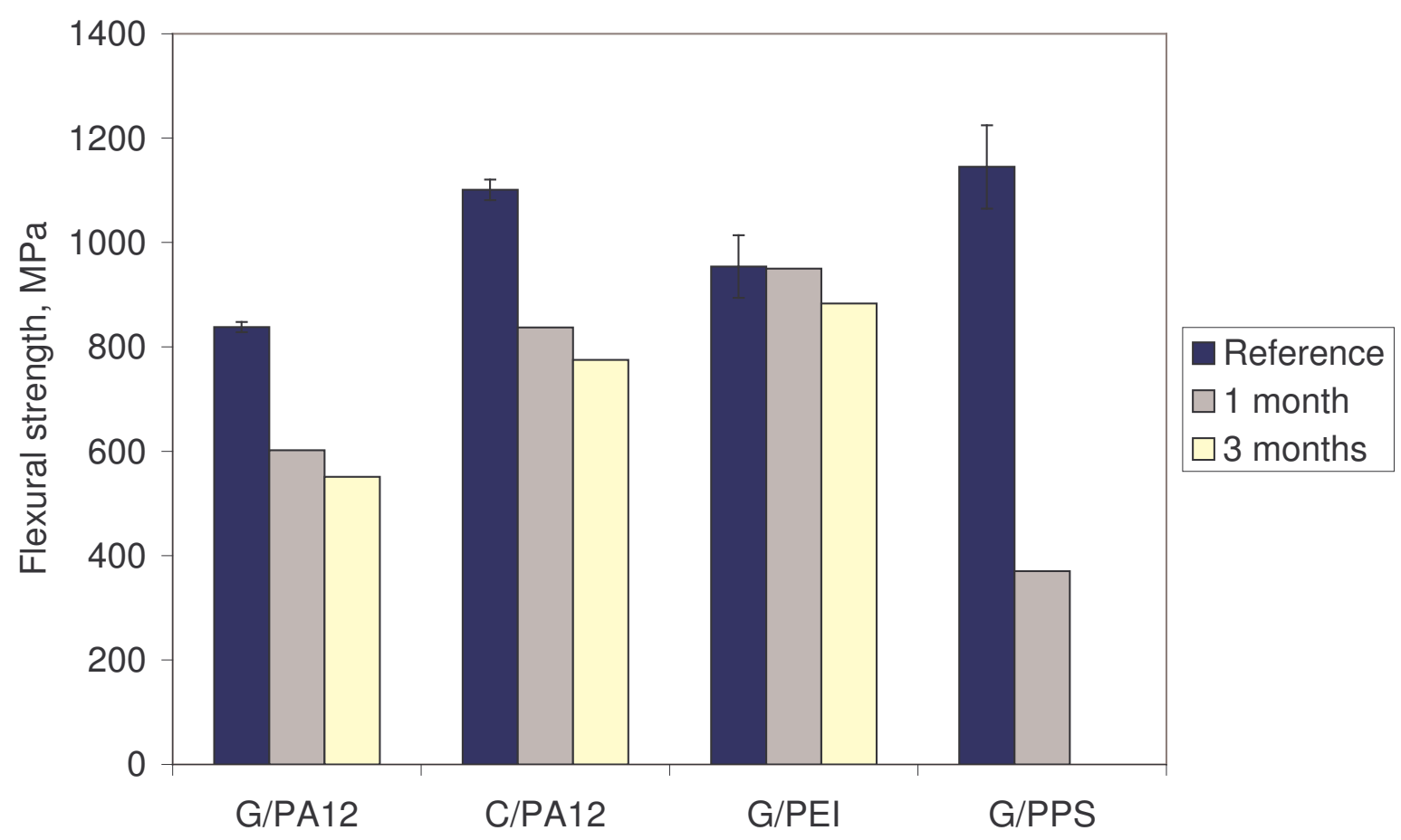

Figure 3. Influence of aging on mean flexural strength values, error bars show minimum and maximum values 


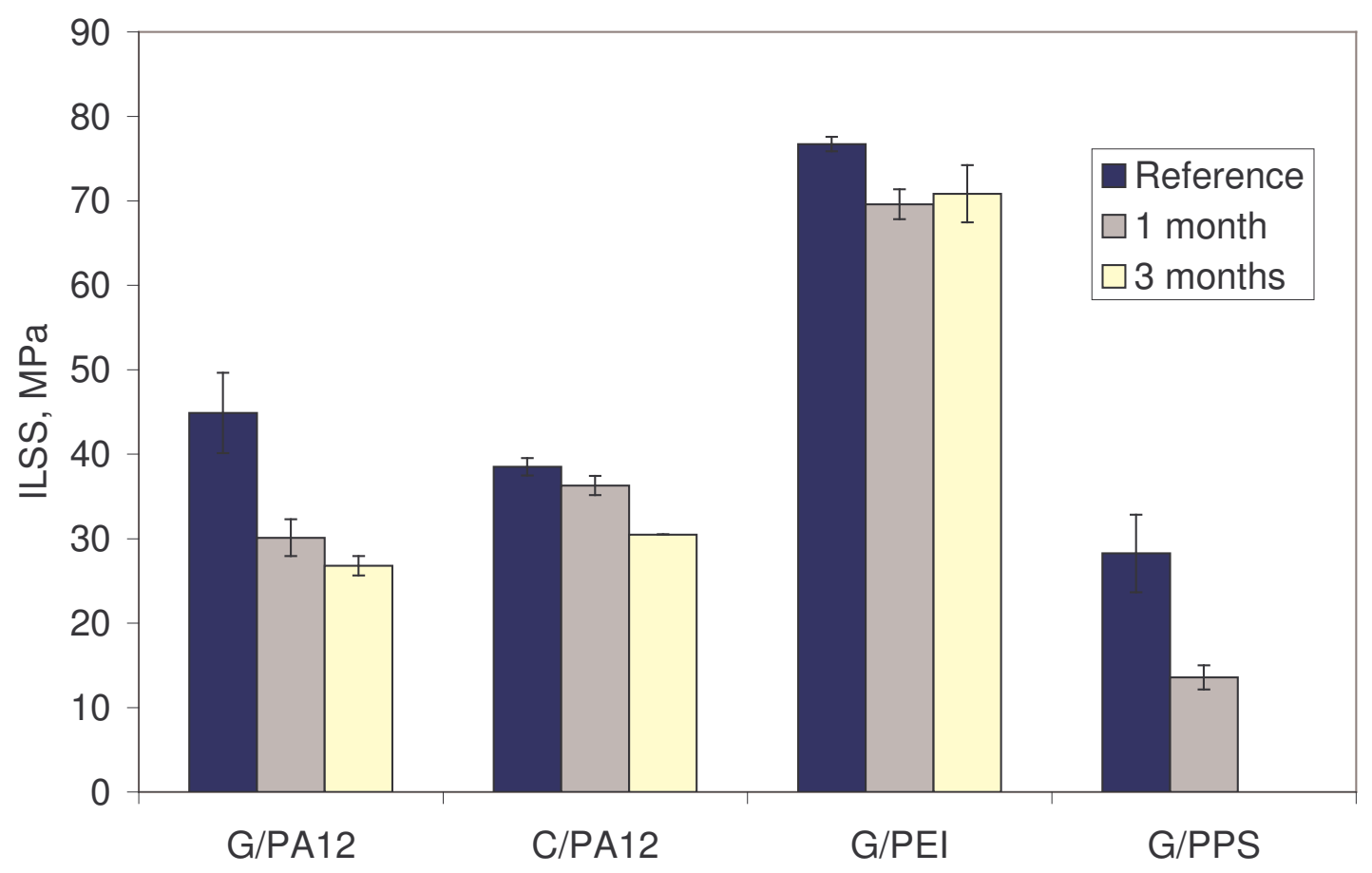

Figure 4. Influence of aging on mean ILSS values, error bars show \pm one standard deviation. 


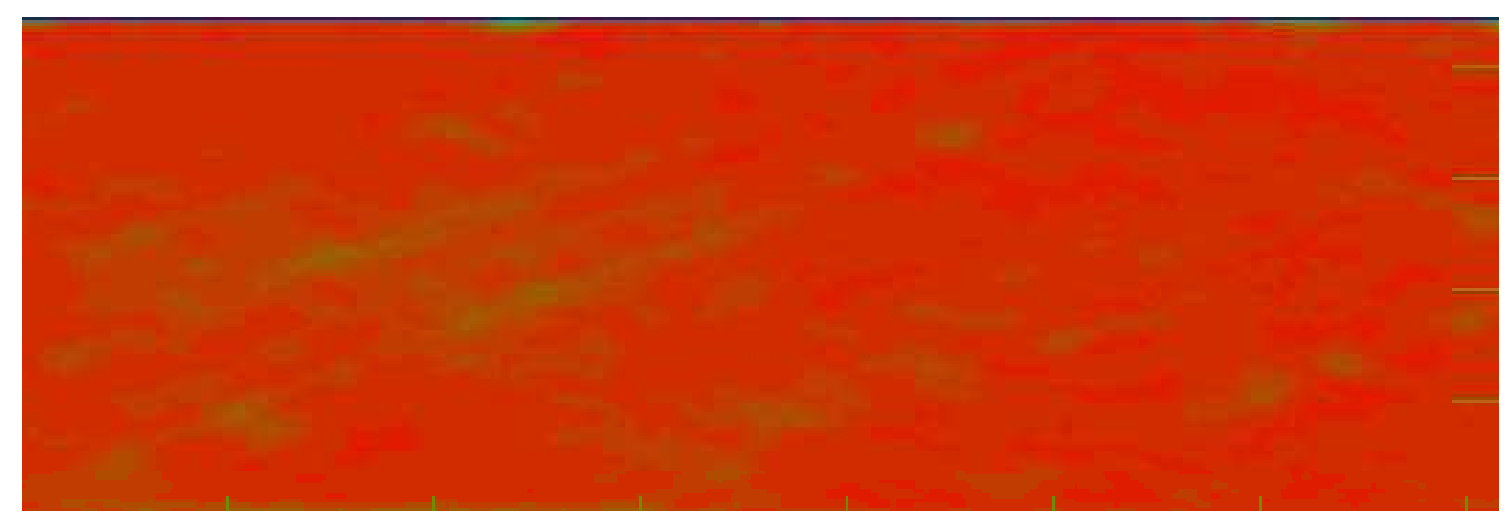

a) Carbon/epoxy

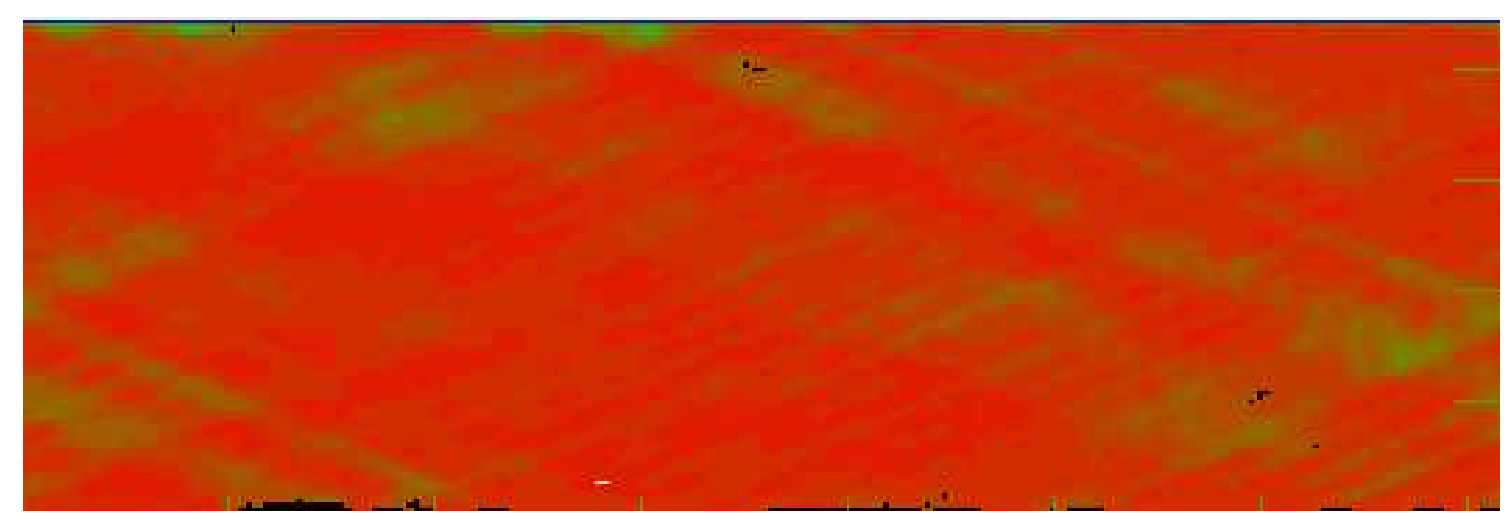

b) Carbon/PEEK

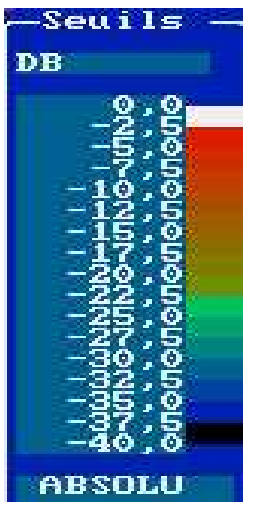

Figure 5. Examples of ultrasonic C-scan maps, $2 \mathrm{MHz}$ focussed transducer, $\mathrm{C} / \mathrm{PEEK}$ and C/Epoxy. 
Apparent interlaminar shear strength, MPa

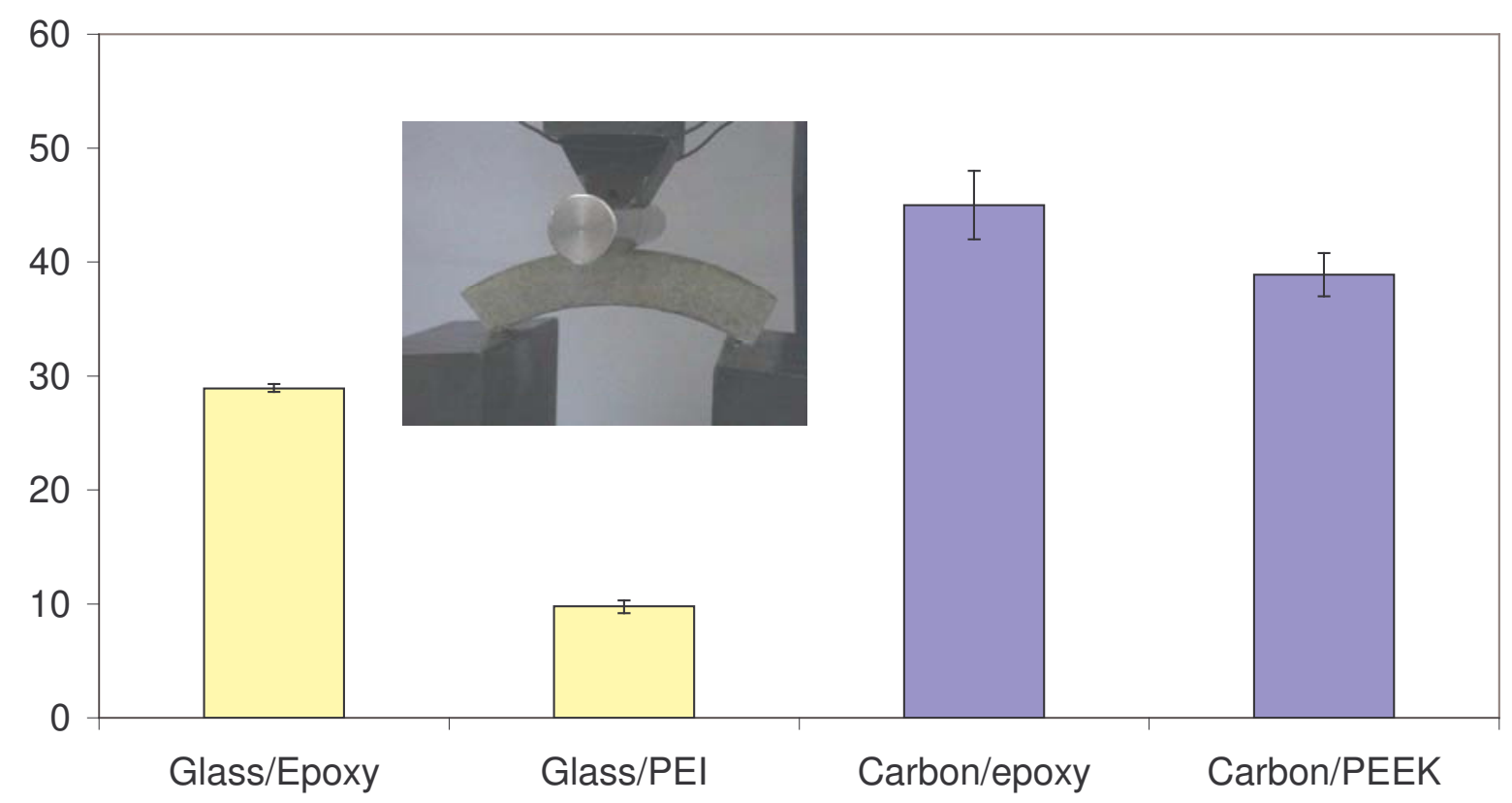

Figure 6. Apparent interlaminar shear strength tests, curved specimens, error bars show \pm one standard deviation insert photo shows specimen of glass/PEI during test 


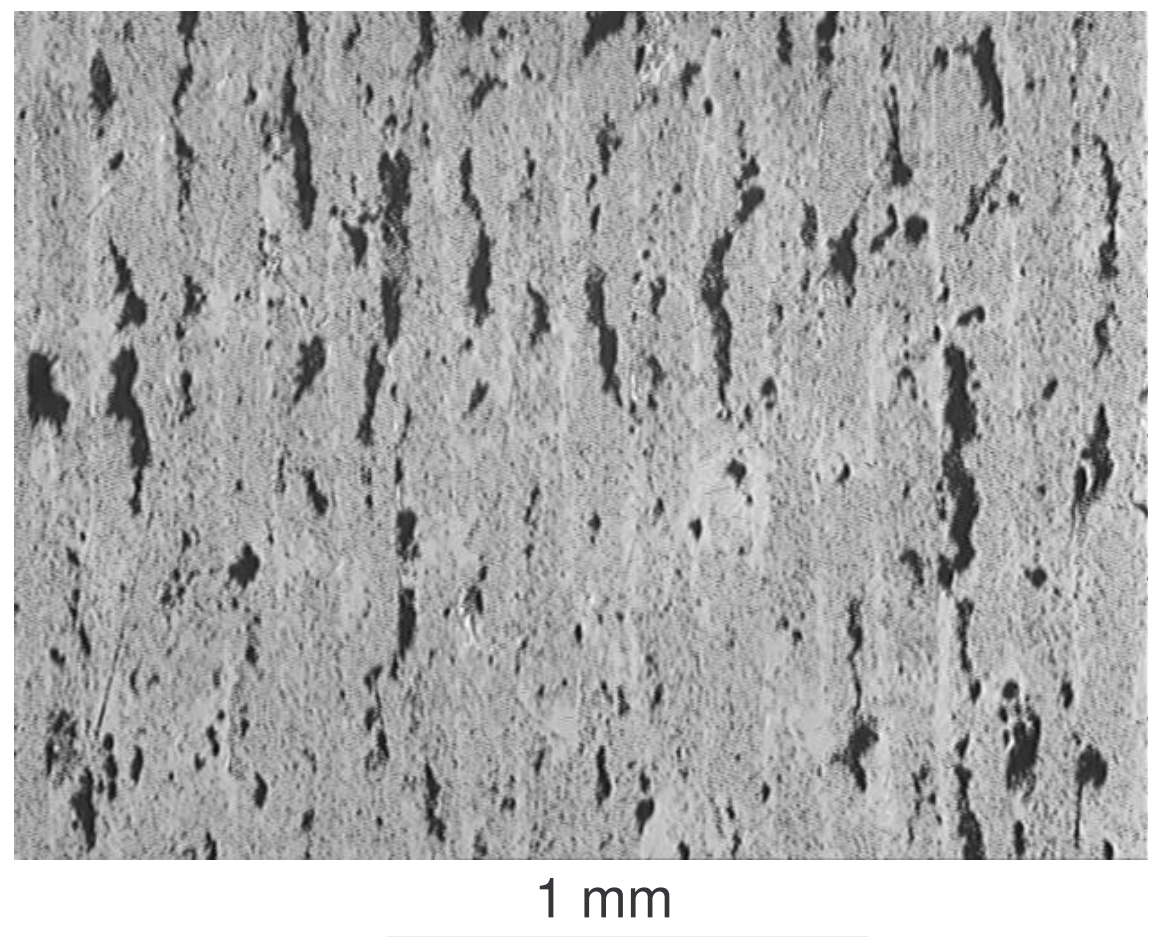

Figure 7. Defects in glass/PEI cylinder wall 


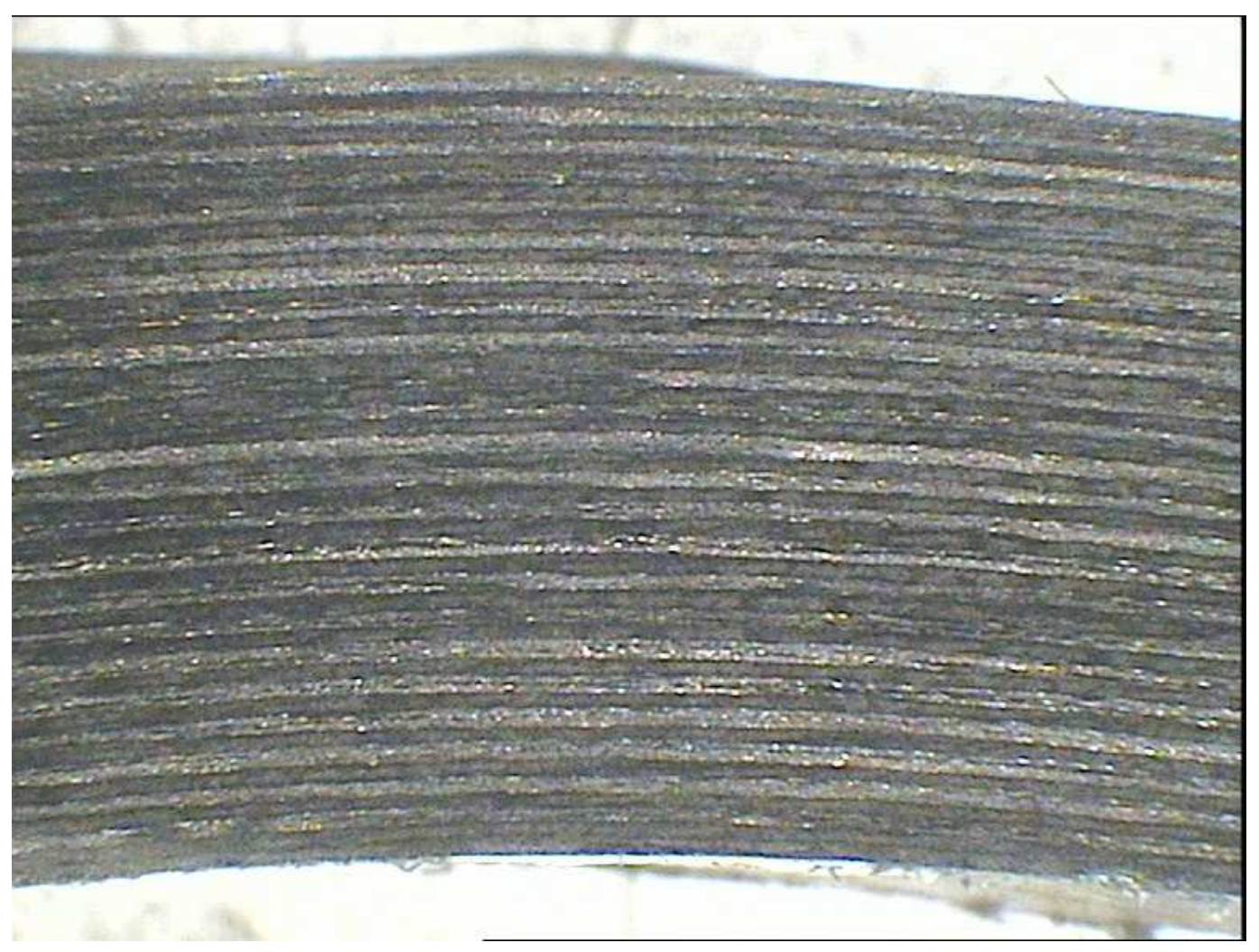

Figure 8 . Section through carbon/PEEK cylinder wall cut at $55^{\circ}$. 


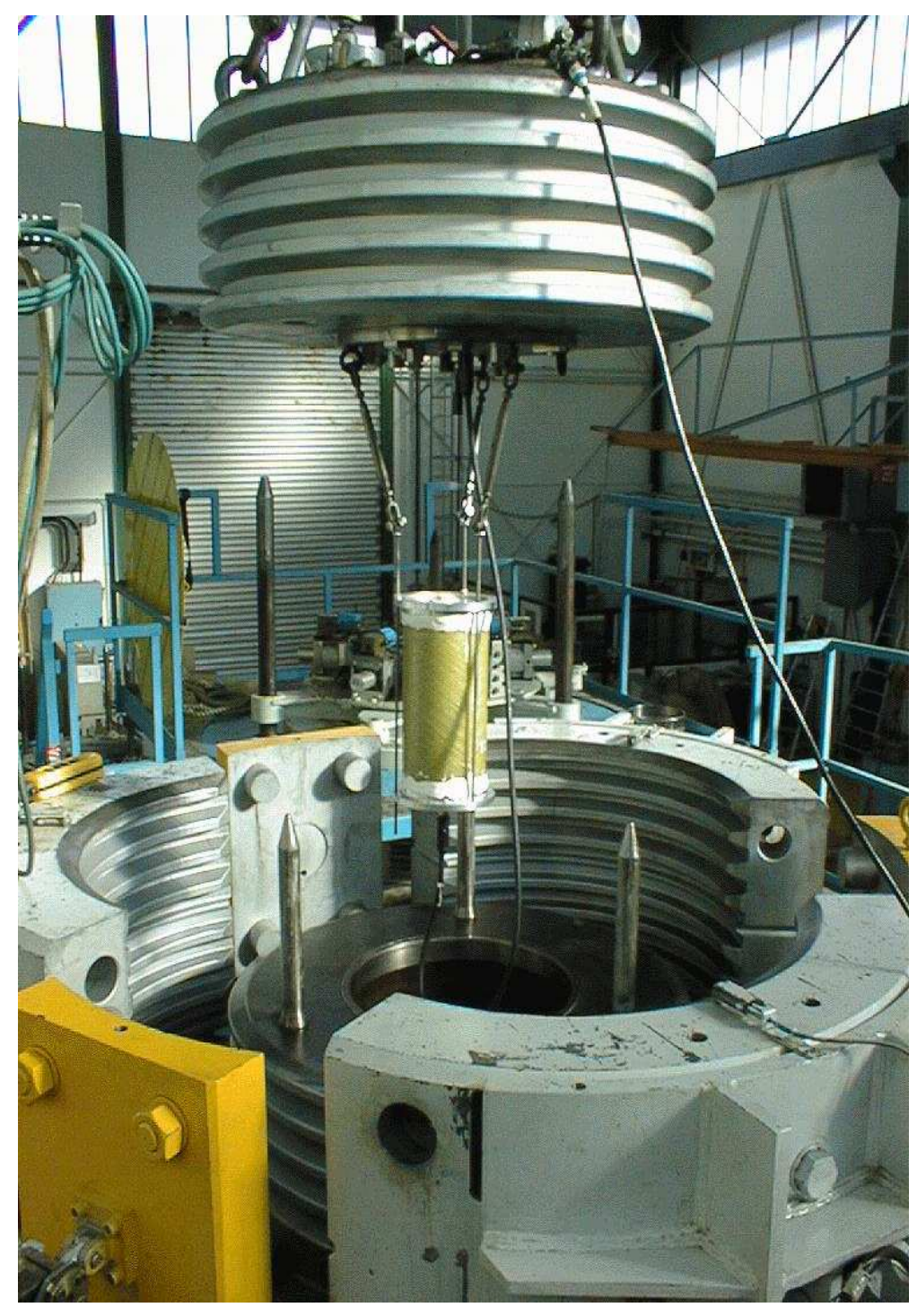

Figure 9. 2400 bar pressure vessel used for implosion tests, showing $175 \mathrm{~mm}$ diameter glass/epoxy cylinder before test. 


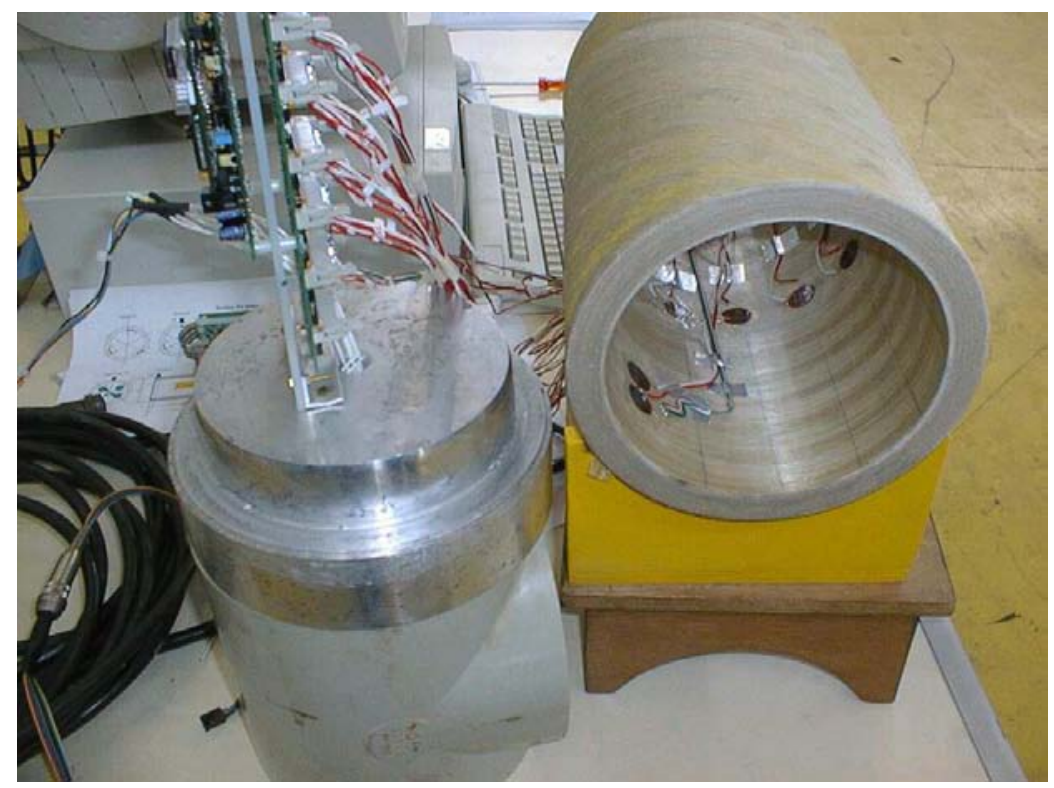

a). Glass/PEI cylinder before test, showing contoured end closure, data acquisition card and strain gauges.

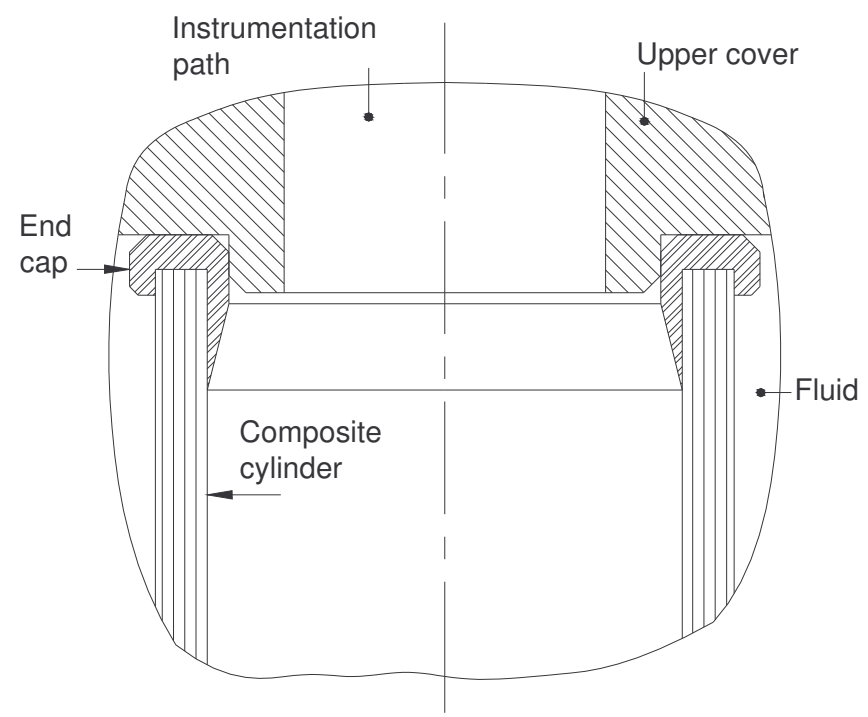

b). Diagram showing aluminium end caps for small carbon reinforced cylinders (drawn to scale).

Figure 10. Experimental fixtures for implosion tests. 
a) Glass/Epoxy

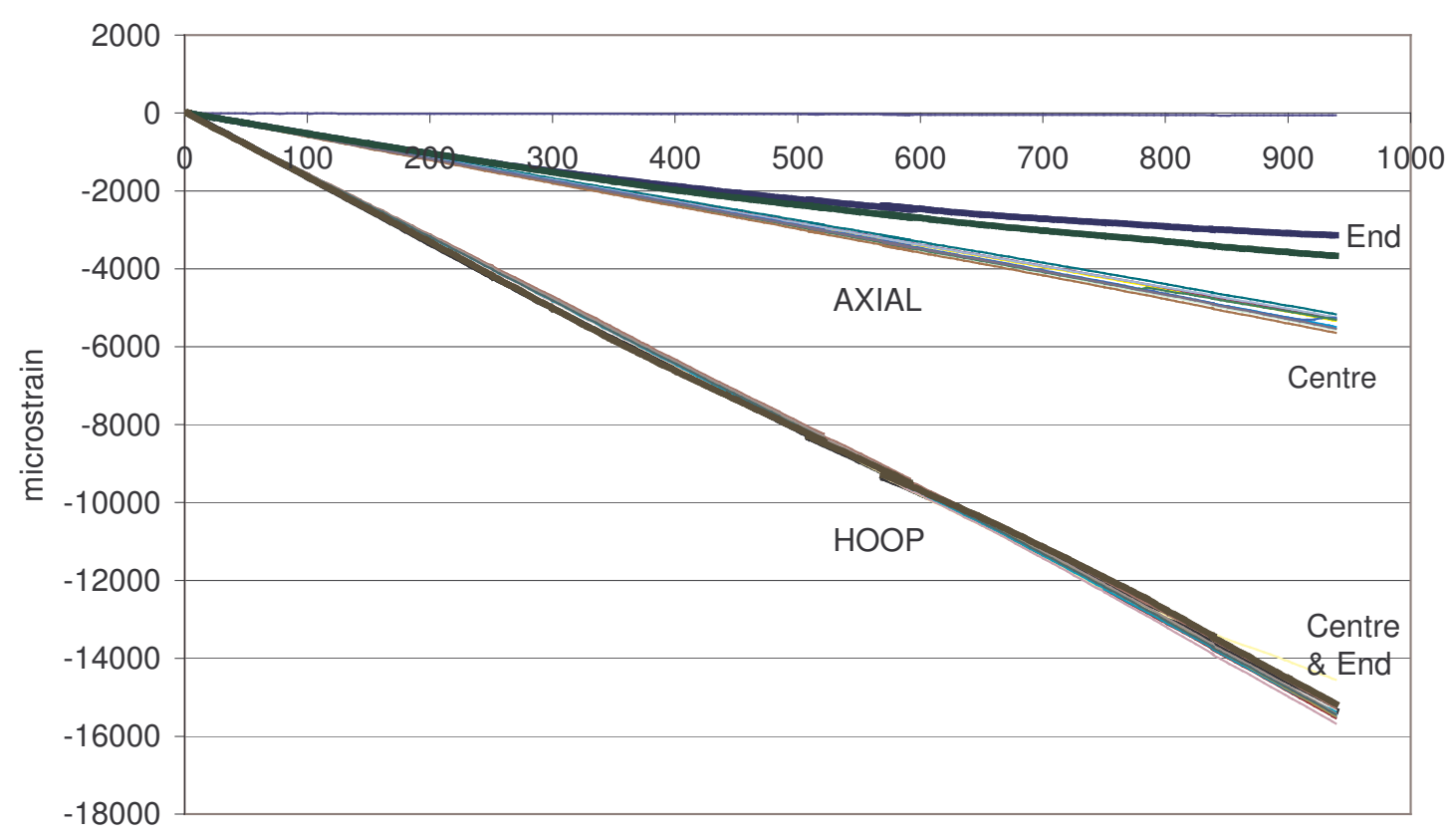

Pressure, bars

b) Glass/PEI

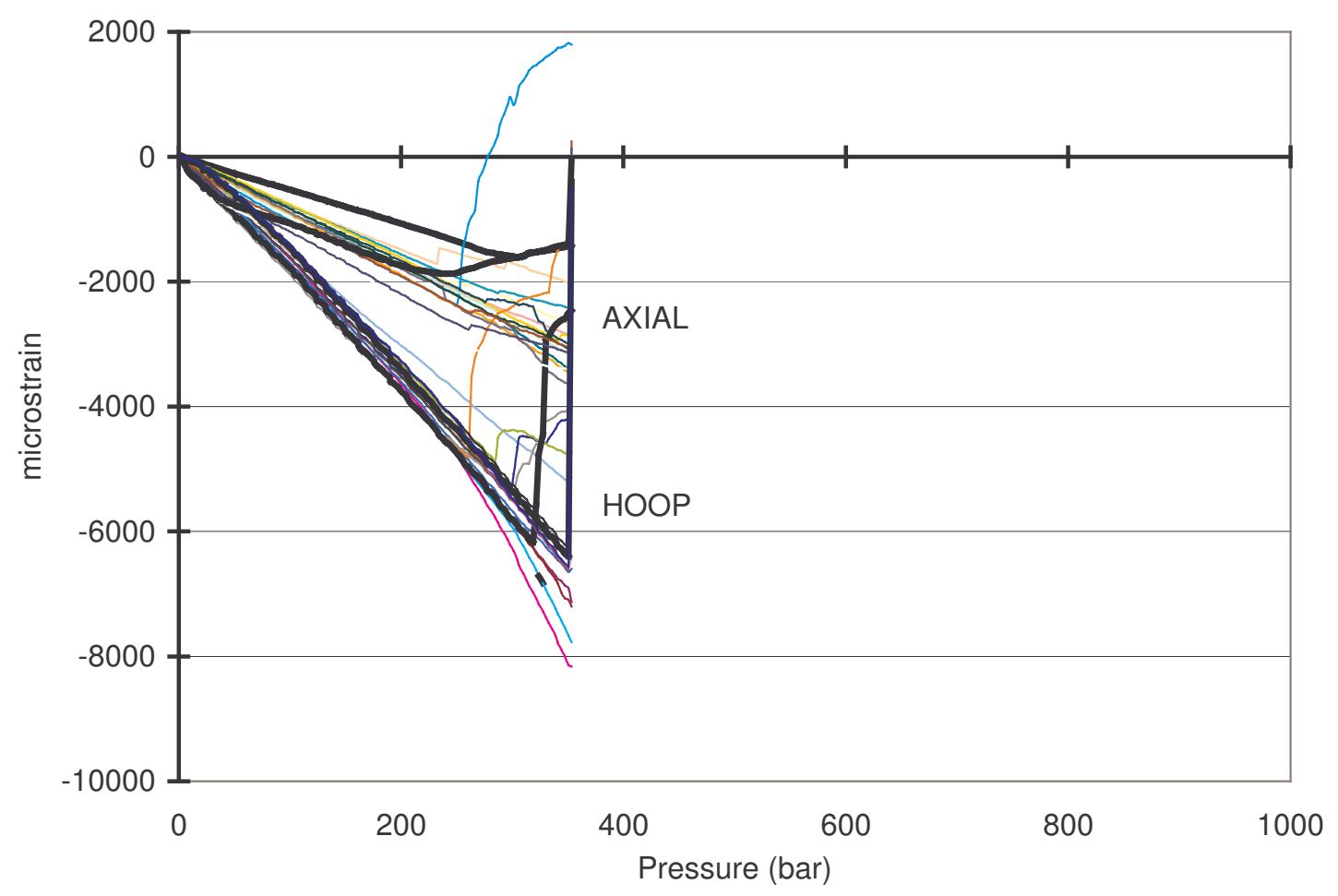

Figure 11. Examples of axial and hoop strain response from 28 strain gauges, 24 at centre and 2 at each end of cylinder a) glass/epoxy and b) glass/PEI.

Bold lines indicate end strain gauge response. 

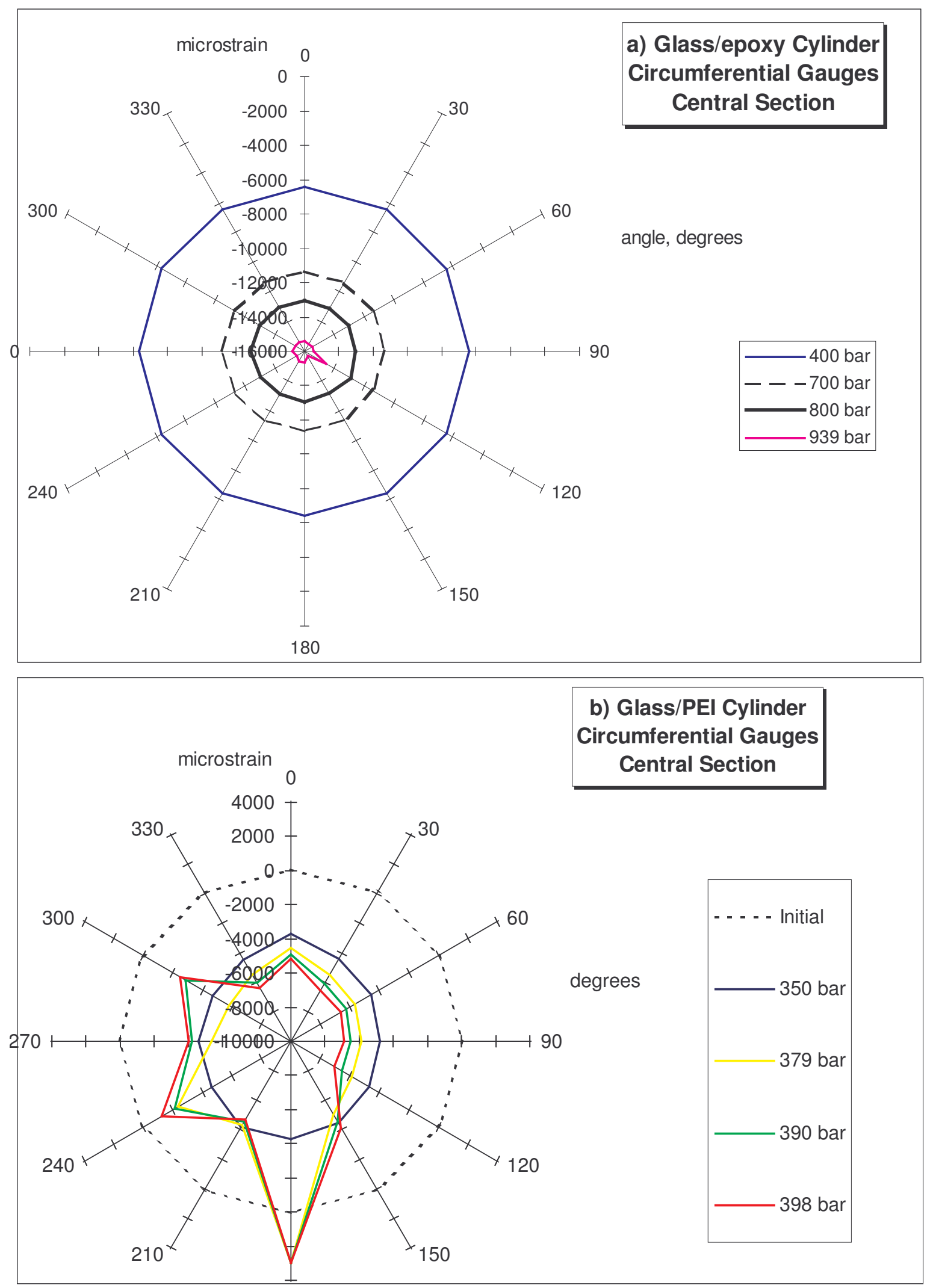

Figure 12. Central section inner wall hoop strains, a), glass/epoxy and b) glass/PEI. 

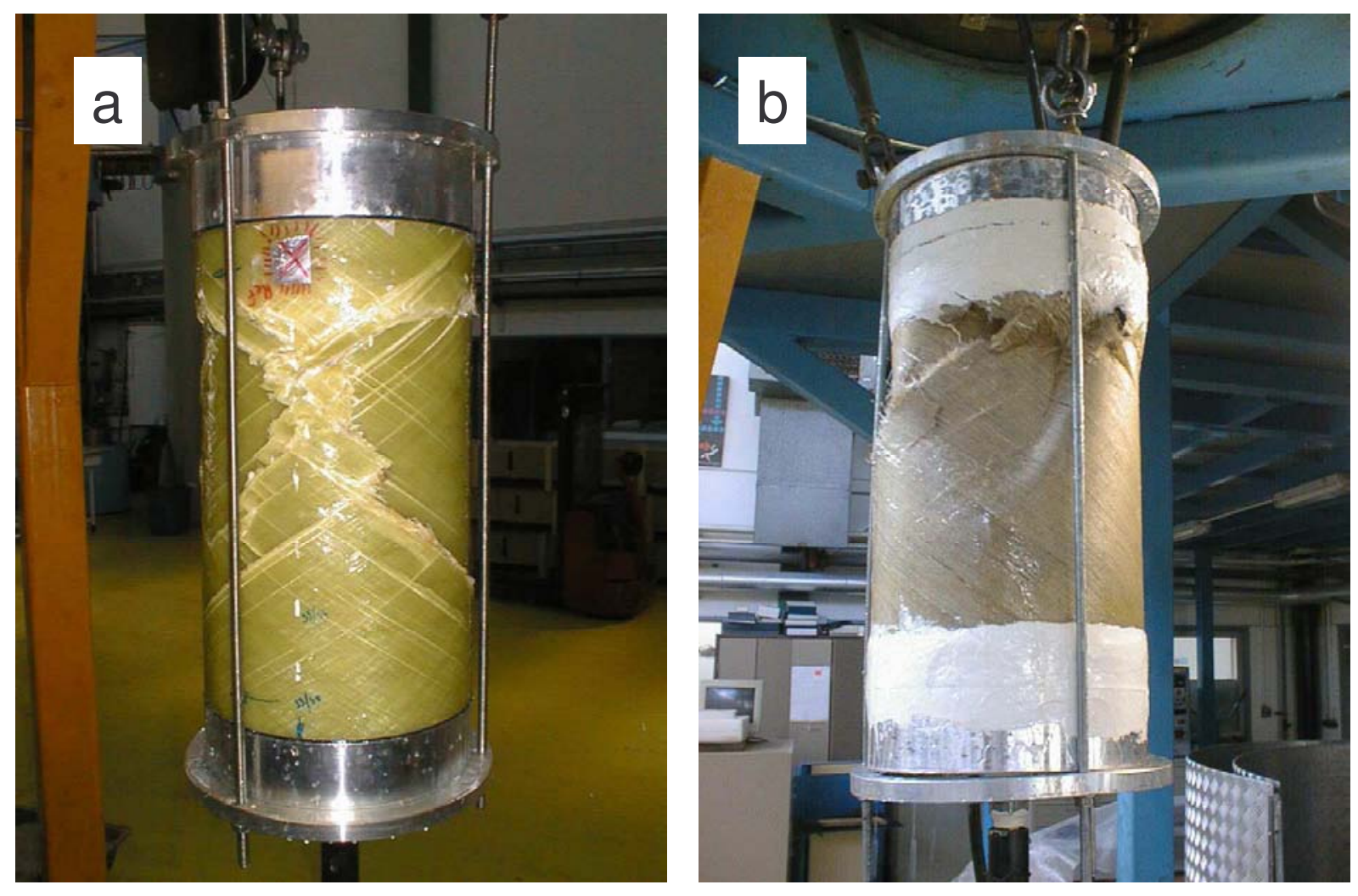

Figure 13. Cylinders after implosion a) glass/epoxy, b) glass/PEI 

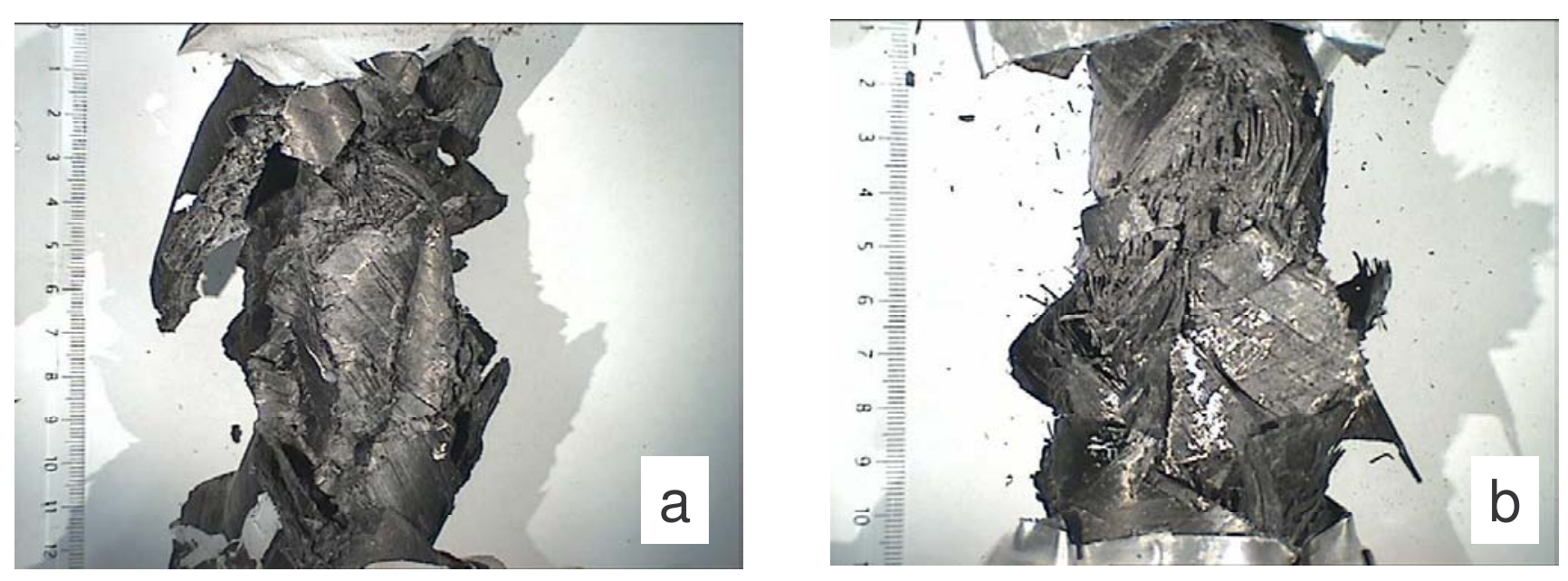

Figure 14. Cylinders after implosion a) carbon/epoxy, b) carbon/PEEK 


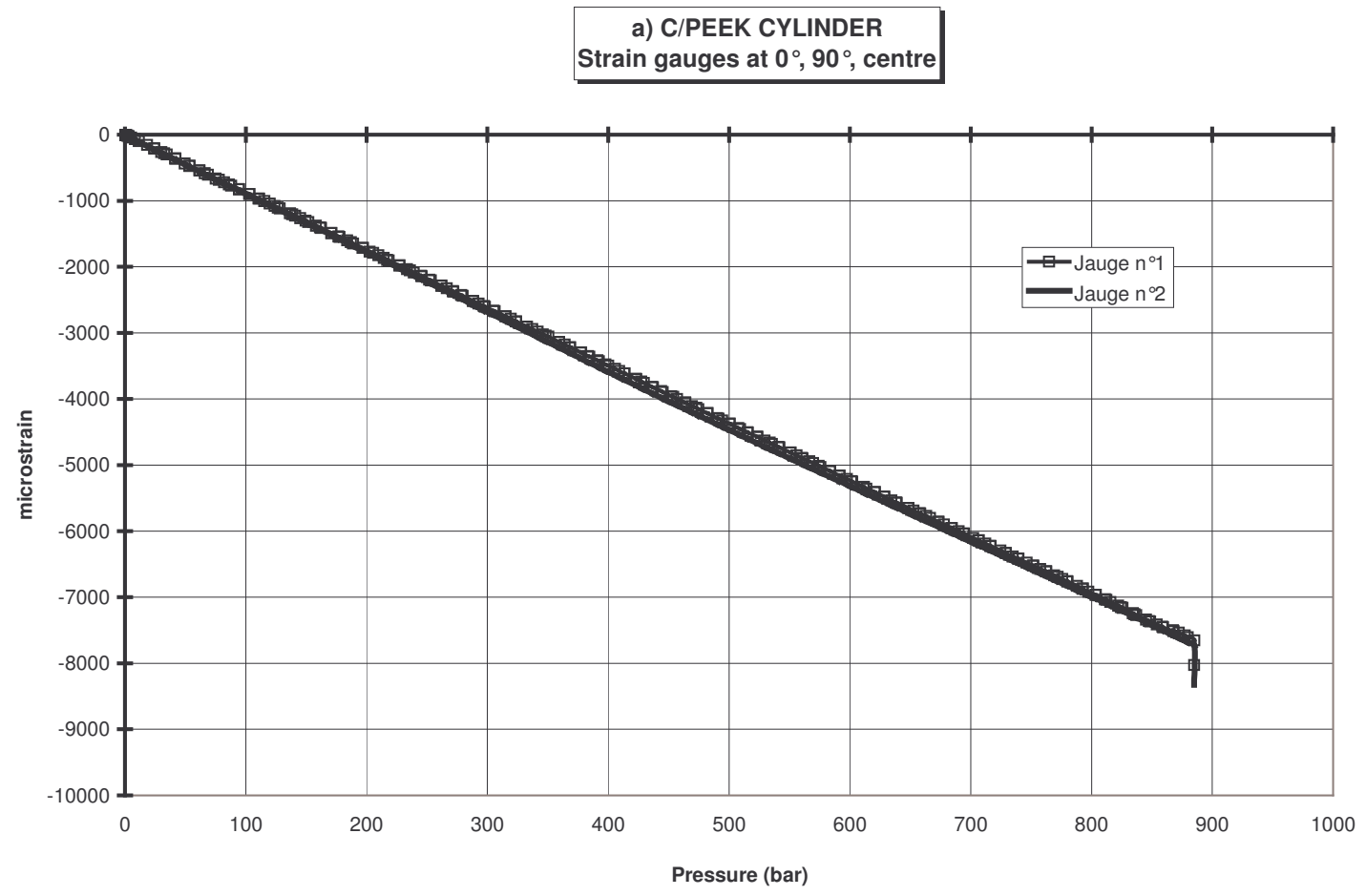

b) C/Epoxy cylinder Gauges at $0,90^{\circ}$, centre

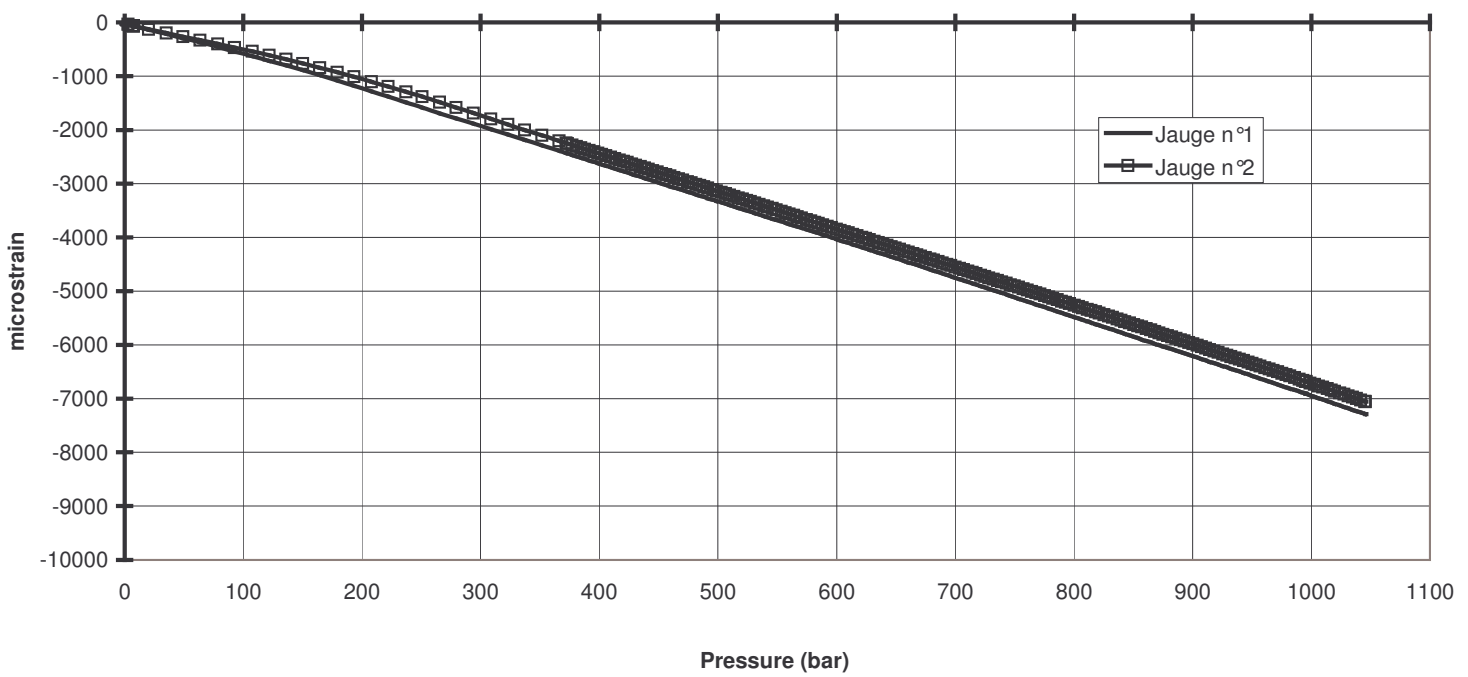

Figure 15. Hoop strain gauge readings, inner wall, mid-height a) carbon/PEEK, b) carbon/epoxy cylinders. 


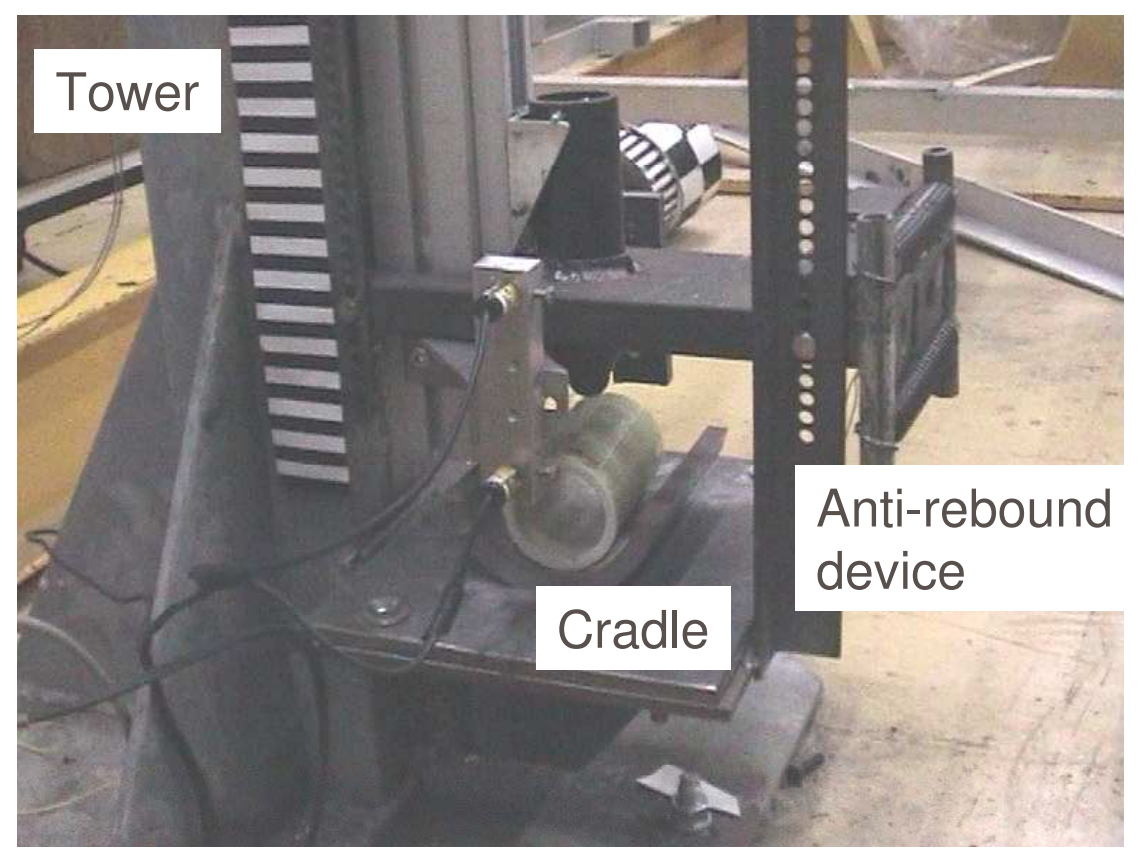

Figure 16. Drop weight impact set-up. 


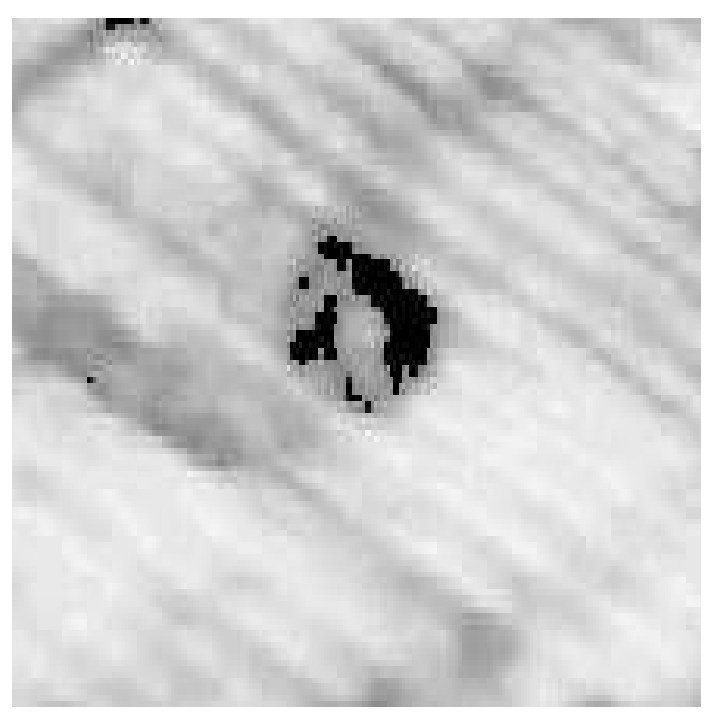

\section{Drop \\ Height}

$50 \mathrm{~cm}$

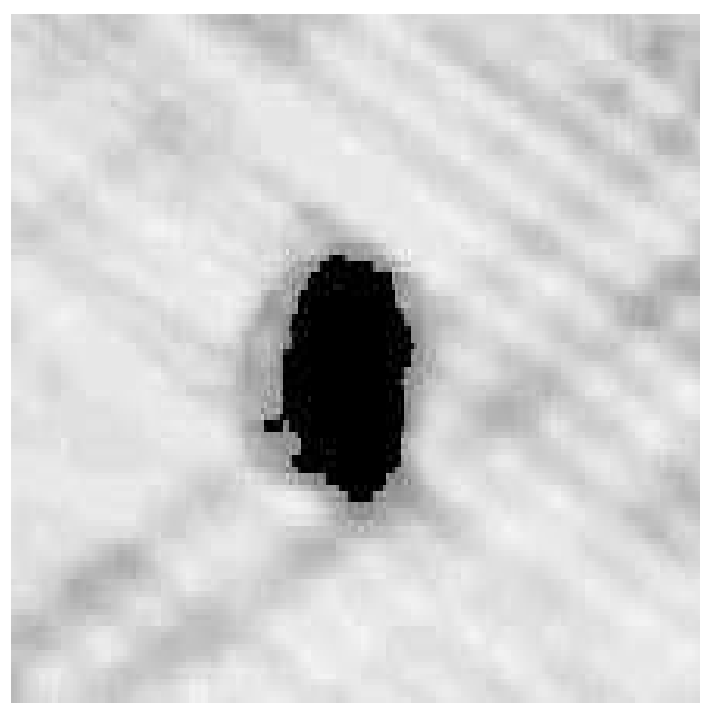

$100 \mathrm{~cm}$
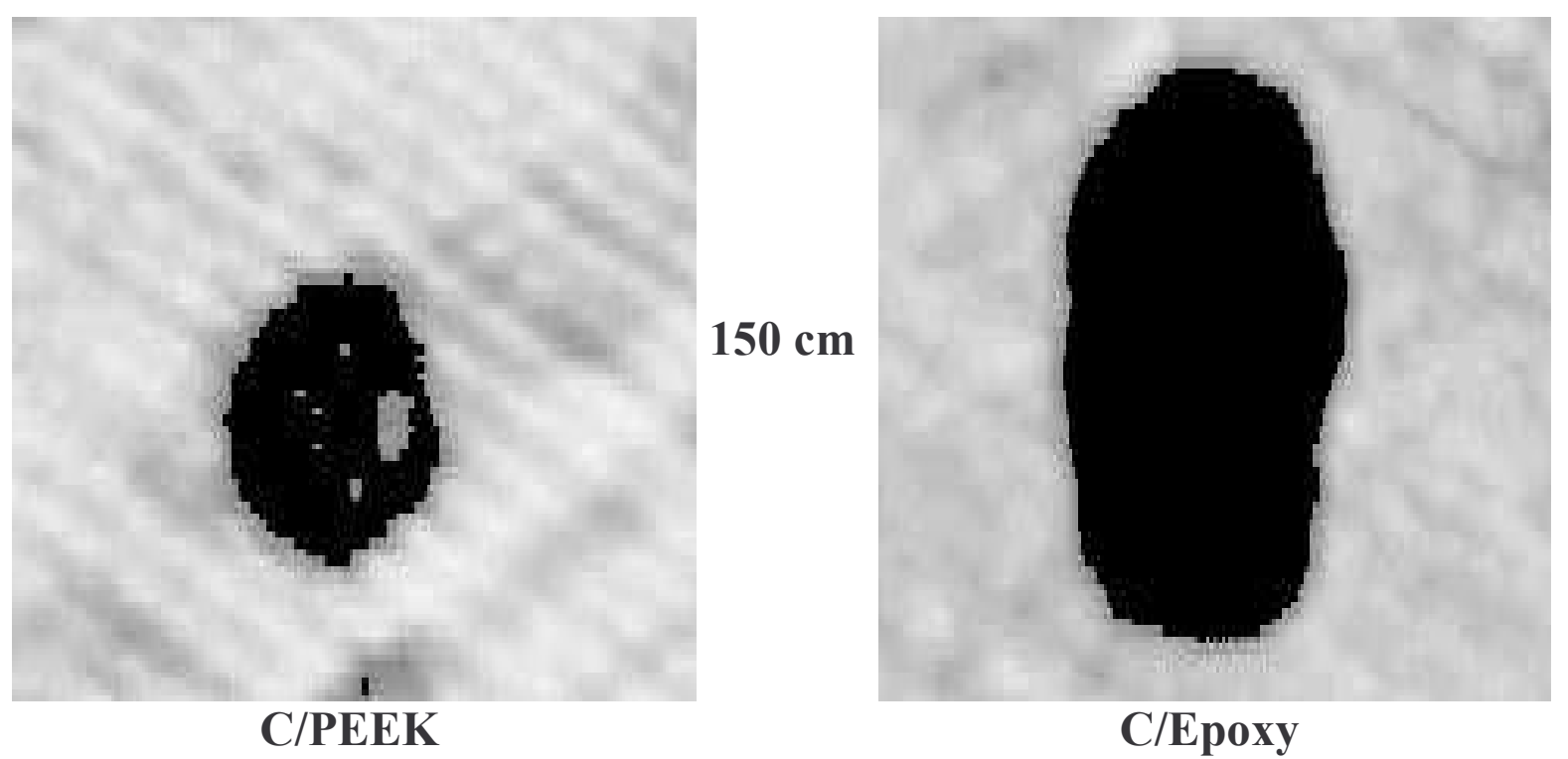

C/PEEK

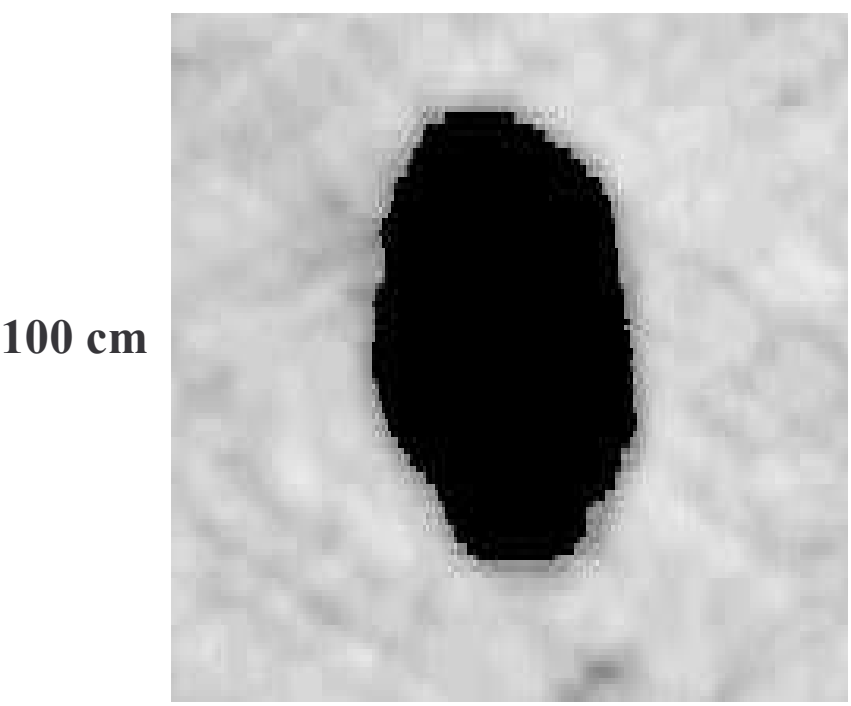

Figure 17. Damaged areas detected by ultrasonic C-scan. Each photo represents an $80 \mathrm{~mm} \times 80 \mathrm{~mm}$ area. 
Projected damage area, C-scan

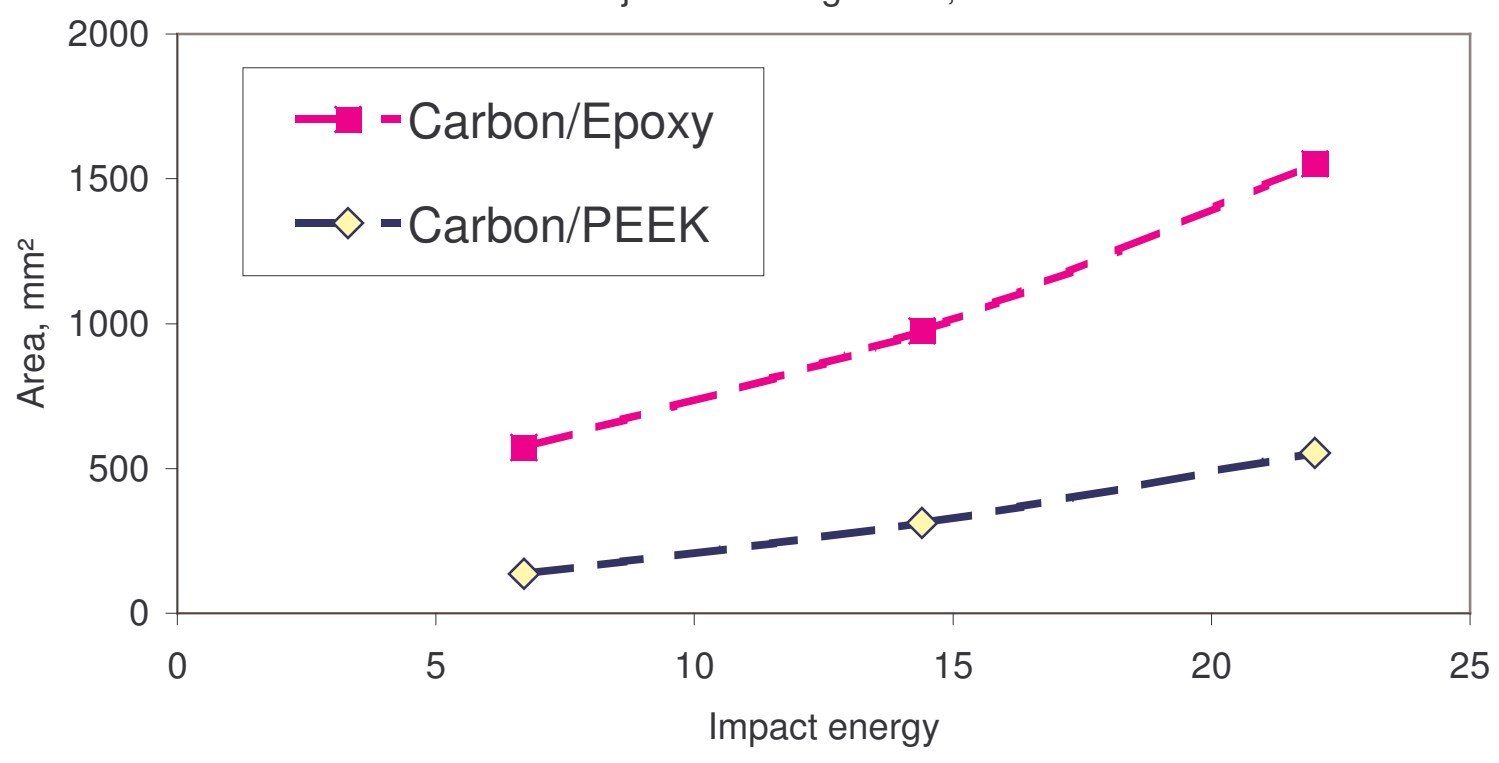

Figure 18. Projected damage area versus impact energy 


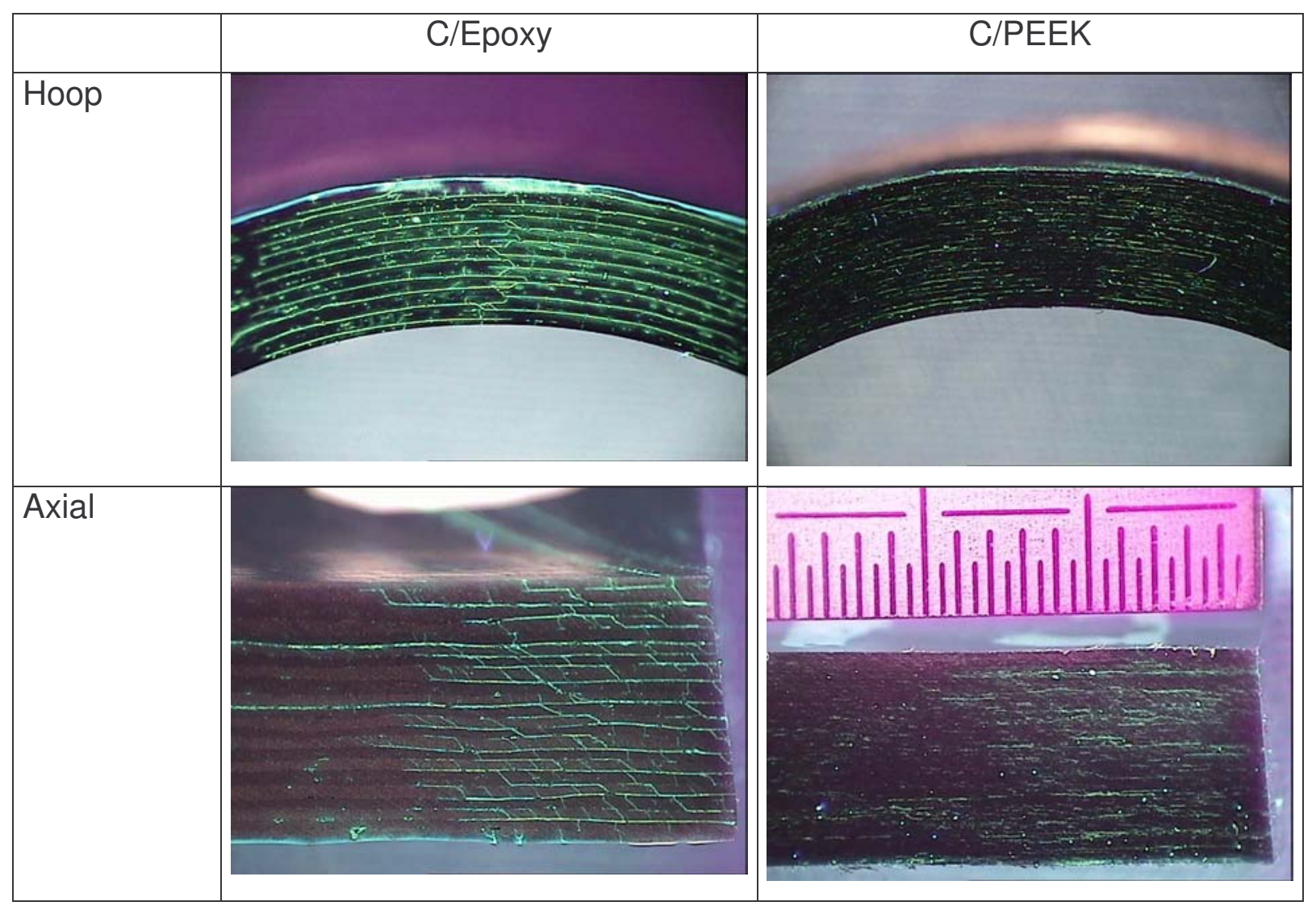

Figure 19. Polished sections of cylinders with dye penetrant showing impact damage in the axial and hoop directions, one meter drop height 
Residual implosion pressure after impact

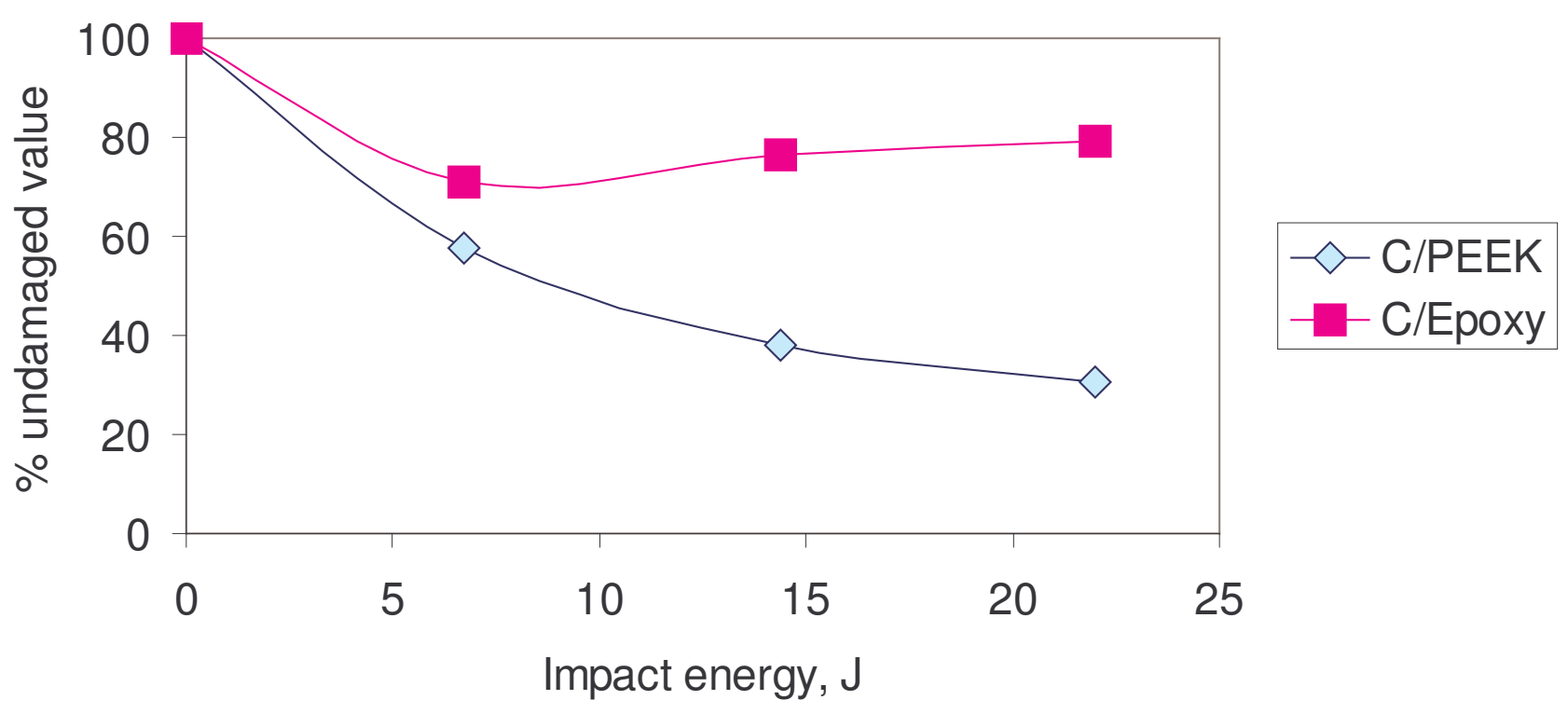

Figure 20. Residual implosion pressure versus impact energy 

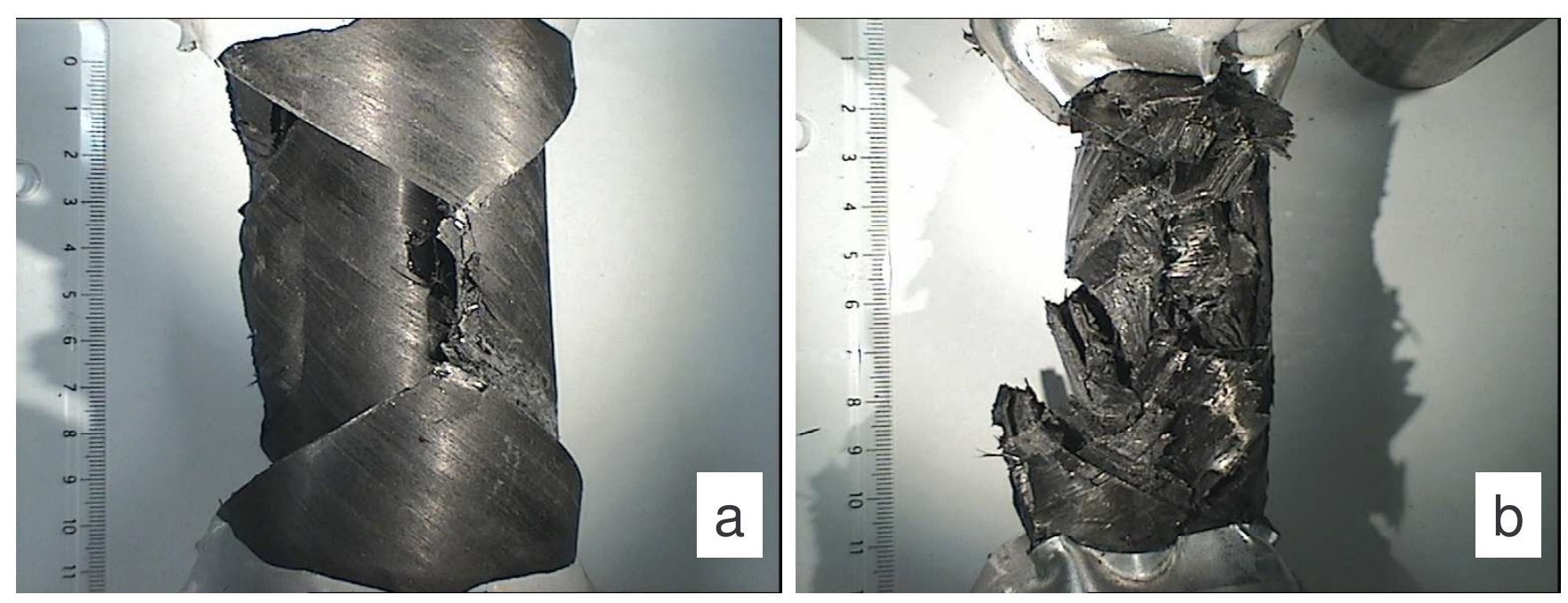

Figure 21. Examples of impacted cylinders after implosion a) $\mathrm{C} / \mathrm{PEEK}$, b) $\mathrm{C} / \mathrm{Ep}$ oxy 